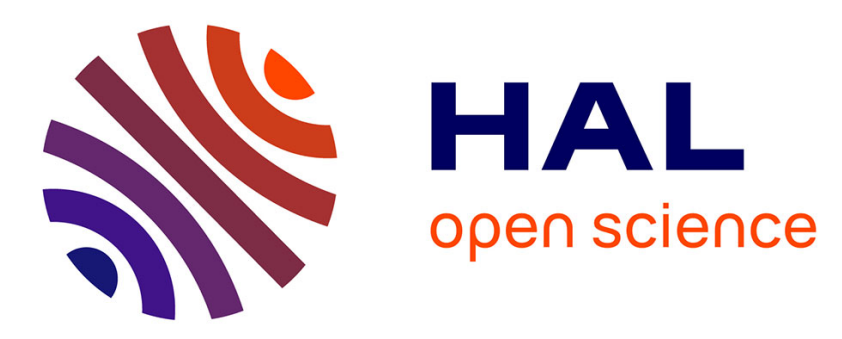

\title{
One step densification of printed multilayers by SPS : towards new piezoelectric energy harvester MEMS
}

Hélène Debéda, Maria Isabel Rua Taborda, U-Chan Chung Seu, Catherine

Elissalde

\section{- To cite this version:}

Hélène Debéda, Maria Isabel Rua Taborda, U-Chan Chung Seu, Catherine Elissalde. One step densification of printed multilayers by SPS: towards new piezoelectric energy harvester MEMS. Cao Giacomo; Estournès Claude; Garay Javier; Orrù Roberto. Spark Plasma Sintering: Current status, new developments and challenges, Elsevier, pp.219-255, 2019, 978-0-12-817744-0. 10.1016/B978-0-12817744-0.00010-6 . hal-02133411

\section{HAL Id: hal-02133411 \\ https://hal.science/hal-02133411}

Submitted on 13 Jul 2020

HAL is a multi-disciplinary open access archive for the deposit and dissemination of scientific research documents, whether they are published or not. The documents may come from teaching and research institutions in France or abroad, or from public or private research centers.
L'archive ouverte pluridisciplinaire HAL, est destinée au dépôt et à la diffusion de documents scientifiques de niveau recherche, publiés ou non, émanant des établissements d'enseignement et de recherche français ou étrangers, des laboratoires publics ou privés. 


\title{
One step densification of printed multilayer by SPS: towards new piezoelectric energy harvester MEMS
}

\author{
Contributed by: \\ Hélène Debéda ${ }^{1}$, Maria-Isabel Rua-Taborda ${ }^{1,2}$, U-Chan Chung ${ }^{2}$ and Catherine Elissalde ${ }^{2}$ \\ ${ }^{1}$ Université de Bordeaux, Laboratoire IMS, UMR 5218, F-33405 Talence, France \\ ${ }^{2}$ Université de Bordeaux, Laboratoire ICMCB, UMR 5026, 33600 Pessac, France. \\ *Corresponding author: helene.debeda@ims-bordeaux.fr
}

Key words: screen-printed, multilayer, energy harvesting, piezoelectric, metal-ceramic assembly, interfaces

\begin{abstract}
Summary: Autonomous electronic devices and increasing use of wireless sensors, which are more and more performant, are facing the problem of energy autonomy. This autonomy can be managed either with a preliminary storage and/or energy harvesting. Hence, since 20 years, the energy harvesting research field is intensive focusing on the development of new materials and their integration in micro/nanogenerators. In this research area, Micro-Electromechanical System (MEMS) energy harvesters (EH) using piezoelectric materials is one of the most promising option because of the availability of mechanical vibrations and of the simply electromechanical conversion. Piezoelectric ceramics, commonly used in various applications, are attractive for $\mathrm{EH}$, and among them, $\mathrm{Pb}\left(\mathrm{Zr}_{1-}\right.$ $\left.{ }_{\mathrm{x}} \mathrm{Ti}_{\mathrm{x}}\right) \mathrm{O}_{3}(\mathrm{PZT})$, despite its lead content, remains mostly studied because of its outstanding properties. For its ceramic process, the main objectives are improved densification, a cost and energy effective processing and integration in microgenerators. In this context, SPS sintering of electroded printed PZT piezoelectric layers supported on stainless steel substrate (SS) is highly challenging. In this chapter, after a section devoted to piezoelectric EH, the device made of screen-printed PZT layers on SS substrate is presented. Then, the authors focus on the strategy to achieve in one step a cantilever transducer where the electroded printed PZT and the SS substrate are co-sintered by SPS. As a first part of this ambitious objective, microstructural, dielectric and piezoelectric properties of the PZT pellet densified by SPS are presented and compared to PZT printed layers conventionally sintered.
\end{abstract}

\section{Introduction}

Piezoelectric vibration energy harvesters $(\mathrm{EH})$ based on $\mathrm{Pb}\left(\mathrm{Zr}_{1-\mathrm{x}} \mathrm{Ti}_{\mathrm{x}}\right) \mathrm{O}_{3}(\mathrm{PZT})$ have received significant attention during these last years because of the simplicity of the piezoelectric electro-mechanical conversion and of the outstanding electromechanical properties of the PZT (S. Tadigadapa et al. 2009). PZT thin films $(<1 \mu \mathrm{m})$ are often deposited onto silicon or metallic supports but are not suitable when large power is required due to their weak electromechanical coupling. PZT thick-films can bridge the 1-100 $\mu \mathrm{m}$ gap between thin films and bulk components (Hinrichsen et al., 2010). They can be formed by the low cost screen-printing technology through a mask using mass-production methods and do not need to be assembled manually, unlike machined ceramics. It is therefore possible to create quite complex structures with a series of relatively simple fabrication steps. Printed-piezoelectric thick-films implemented on metallic substrates instead of silicon substrates already confirmed their excellent performances such as flexibility, toughness, and high-efficiency of power generation (Zhu et al., 2011). Here, the objective is to develop a printed low cost vibration piezoelectric energy harvester 
based on densified PZT with microstructure and electromechanical properties approaching those of commercial PZT ceramics. The energy harvesting microsystem consists in a three-dimensional thickfilm structure made of a thick PZT layer sandwiched between two gold electrodes deposited on a stainless steel substrate (SS). Because of the residual porosity observed in the fired PZT printed film due to the removal of the organic binder before the firing, improved densification can be obtained by adding an additional isostatic step before the firing (Debéda et al, 2005). Also, as shown in previous work, a better compacity of the PZT thick films fired at $900^{\circ} \mathrm{C}$ can be observed when the PZT powder is mixed with the eutectic phase $\mathrm{LBCu}$ instead of the borosilicate glasses (Debéda et al., 2015). Sintering without additives are nevertheless preferred to achieve the best electromechanical properties. The co-sintering of the printed multilayer Au/PZT/Au by Spark Plasma Sintering (SPS) represents a great challenge and possible ways to achieve this are explored. Original routes are proposed that would have significant advantages over classical densification routes: increased compacity while reducing the firing temperature, no use of mineral binder to not affect the electromechanical properties and no need of a pressure step before the firing.

In this chapter, the first section is devoted to basics on piezoelectric effects, before a focus on the energy harvesting application where piezoelectric transduction allows capture of vibrations. The requirements of both the electromechanical properties of the piezoelectric material and the design of the piezoelectric energy harvester are then described. Some examples of successful piezoelectric vibration $\mathrm{EH}$, based on various piezoelectric materials and using different processes are shown. In the third section, the fabrication steps of the screen-printed energy harvester fabricated with the conventional screen -printing thick film technology are detailed. Then, in the last section, referring to literature, we will first discuss about the sintering of PZT by SPS underlying also the drawbacks and limitations. Then our approach is illustrated aiming one step sintering of PZT by SPS, avoiding both the use of sintering aids and post-annealing treatment. The key role of the processing conditions is pointed out with emphasis on the correlation between microstructural features and dielectric and piezoelectric performances of the ceramics. Finally, the most challenging part of the work is presented with the first attempts of the EH multilayer sintering by SPS.

\section{Basics on piezoelectric vibration energy harvester}

\section{II.1.Piezoelectric effect}

\section{II.1.1. Historic and applications}

The root of the word piezo means pressure; hence, the original meaning of the word piezoelectricity is "pressure electricity", the generation of electric field from applied pressure. This definition ignores the fact that the piezoelectric effect is reversible, allowing the generation of mechanical motion by applying a field. Piezoelectricity was discovered by Pierre and Jacques Curie in 1880 in single crystals such as Rochelle salt and quartz. It is only in 1946 that scientists discovered that the barium titanate $\mathrm{BaTiO}_{3}$ is piezoelectric (Jaffe et al., 1971). With its increased sensitivity and higher operating temperature, $\mathrm{PbZrTiO}_{3}$ (PZT) soon replaced $\mathrm{BaTiO}_{3}$ in many existing devices and is still the most widely used piezoceramic today. With the apparition of Internet Of Thing (IOT) and because of the 
brittleness of the piezoceramics, piezoelectric composites and polymers are nowadays more and more studied for instance for wearables because of their flexibility and conformability (Zeng et al. 2014 ). However, their properties remain lower than those of the piezoceramics (Tadigadapa and Mateti, 2009). The piezoceramics can be found in a broad range of applications using either the direct or inverse piezoelectric effect. They are present in every day, for example in cleaning application for jewelry, glasses or teeth using generators of ultrasonic applications, but also in high-end technology markets such as medical technology, semiconductor technology or mechanical and automotive engineering. Examples of applications are listed below:

- Transducers for sound and ultrasound in air (microphones, intruder alarm system, loudspeakers, etc),

- Sensors (pressure, accelerometers, chemical, ultrasonic sensors for medical applications, etc), Structural Health Monitoring (SHM),

- Actuators, motors, transformers,

- Resonators and filters, push buttons and keyboard, inkjet printers, flowmeters, micropositionned devices (optics, microscopes), etc.

Energy harvesting applications are also more and more needed with the growing of this intelligent world surrounding us. This new field of research is looking for alternative autonomous power supplies for all the wireless connected devices currently powered by batteries. Vibration piezoelectric energy harvesters where the direct piezoelectric effect is involved can be a solution to avoid recharging or replacing the batteries. Basics on piezoelectric energy harvesters are given in the next paragraph.

\section{II.1.2.Description and origin of the piezoelectric effect}

Illustration of the piezoelectric effect is shown figure 1a. In the direct piezoelectric effect, also called generator or sensor effect, pressure generates charges on the surface of the piezoelectric materials. The field produced by the applied stress can be detected as an electric voltage if the piezoelectric body has electrodes. The sign of the voltage depends on the stress, compressive or tensile. With this direct effect, mechanical energy is converted into electrical energy. Conversely, if an electric field acts on a piezoelectric body, a distorsion happens in it. This inverse effect also called actuator effect converts electrical energy into mechanical effect. Of course, the expansion produced in one direction may be compensated by a contraction in the two other directions, resulting in no change in volume. However, in some materials, a volume change can occur. In all cases, when amplifications by mechanical resonance is not involved, the deformations are very small.

The occurrence of piezoelectricity is due to the lack of a center of symmetry in the unit cell of the crystal. Consequently, as a result of the stress, a net movement of the positive and negative ions with respect to each other produces an electric dipole (polarization). This piezoelectric effect is linear and reversible, and the sign of the produced charge is dependent on the direction of the stress (tensile or compressive). Figure $1 \mathrm{~b}$ illustrates the origin of the piezoelectric effect in the quartz. Among the 32 crystallographic classes, 21 do not possess a center of symmetry and 20 of these are piezoelectric. Some piezoelectric crystals, like the quartz only develop the polarization when the force is applied, while others are already polarized without pressure applied. The well-known materials barium titanate $\left(\mathrm{BaTiO}_{3}\right)$, lead titanate $\left(\mathrm{PbTiO}_{3}\right)$ or lead zirconate titanate $\left(\mathrm{PbZrTiO}_{3}\right)$ belong to the piezoelectric 
family which exhibit self-polarization: they are ferroelectric materials. However, the spontaneous polarization in a polycristalline material such as ceramics is random and a polarization process (or "poling process") is necessary to obtain a macroscopically piezoelectric ceramic. During this process, the domains within grains can orient in the direction of the direct current electric field applied at a temperature slightly below the Curie temperature (Fig.2). A remanent polarization is thus achieved within the polycrystalline material after the removal of the field.

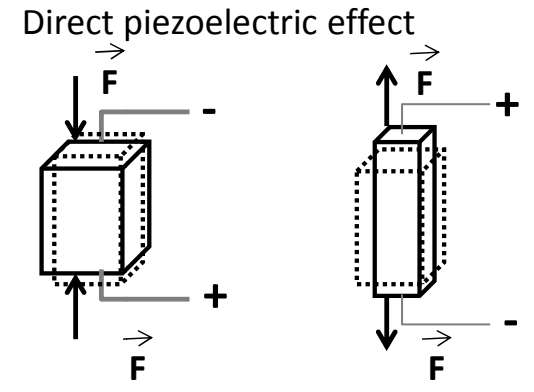

Inverse piezoelectric effect
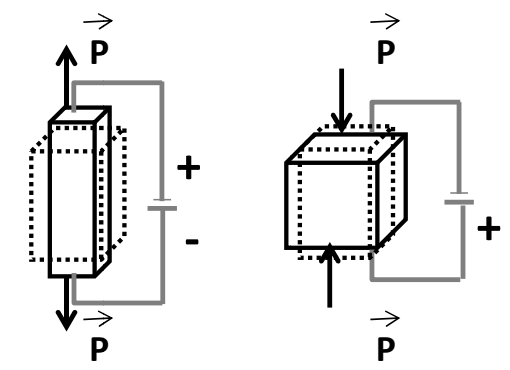

a)

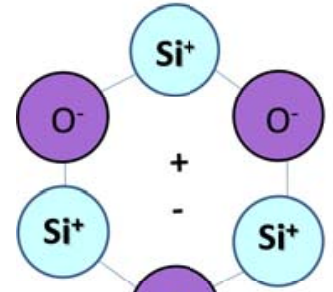

0.

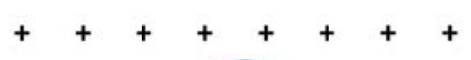

$\mathrm{Si}^{+}$

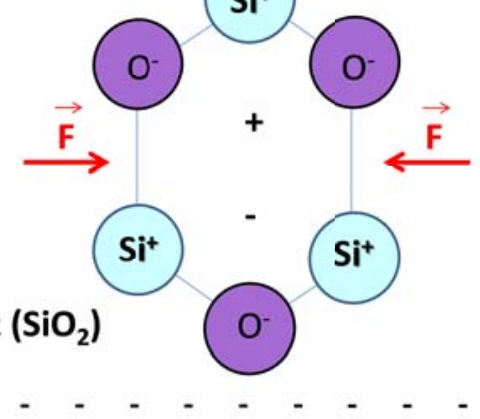

b)

Figure 1: a) Illustration of the piezoelectric effect and b) Origin of the piezoelectric effect in the unit cell of a disc of quartz cut with it normal surfaces normal to the axis of non-symmetry

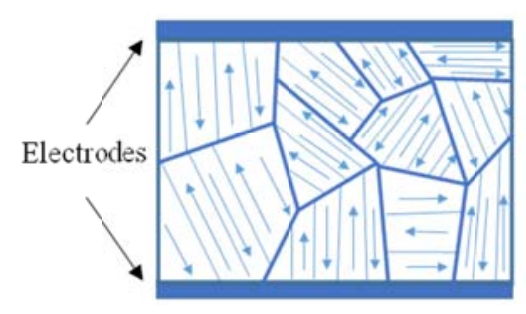

Random orientation of polar domain prior to polarization

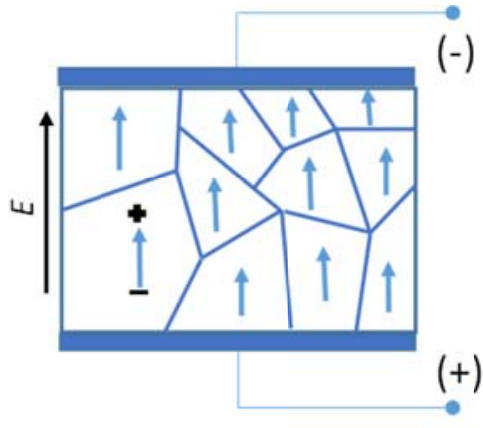

Polarization in DC electric field $E$

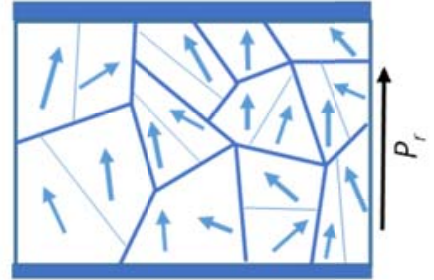

Remanent polarization $P_{r}$ after poling. $\mathrm{T}<\mathrm{Tc}$

Figure 2: Polarization steps in ceramics

\section{II.1.3.Electromechanical data and equivalent circuit at resonance}

The piezoelectric material converts electric field into mechanical displacements and vice versa. With the aids of the known four pole theory (Fig. 3a), mechanical characteristics can be linked with electrical characteristics through basic relationships (equations 1 and 2). In these equations, connection 
between the mechanical and electrical characteristics is done using $d$ piezoelectric coefficients. It is worth noting that these equations can be applied only to small electrical and mechanical amplitudes.

$$
\begin{gathered}
S=s^{E} T+d E(\text { converse piezoelectric effect) (Eq.1) } \\
D=d T+\varepsilon^{T} E(\text { direct piezoelectric effect) (Eq.2) }
\end{gathered}
$$

Where $S, T, D$ and $E$ are respectively the strain, stress, electric displacement and electric field vectors, and $\varepsilon, s$ and $d$ are respectively the dielectric constant, compliance and piezoelectric strain coefficients matrix. The subscripts denote the constant quantity.

High $d$ piezoelectric strain coefficient, relating the strain developed to the applied field, will be hence preferred for sensors. Note that the matrices representing the piezoelectric coefficient is not full and it is more convenient to specify subscript notation (Fig. 3b). In general, the " 3 direction" is determined as the polarization direction. The matrix of the piezoelectric coefficients will be hence revealing the ceramic symmetry:

$$
[d]=\left[\begin{array}{llllll}
0 & 0 & 0 & 0 & d_{15} & 0 \\
0 & 0 & 0 & d_{15} & 0 & 0 \\
d_{31} & d_{31} & d_{33} & 0 & 0 & 0
\end{array}\right]
$$

In this matrix, for MEMS based for instance on films of AlN, ZnO and PZT, $d_{33}$ and $d_{31}$ are for instance the most common piezoelectric coefficients. The first 3 subscript refers to the displacement or electric field 3 direction, whereas the second subscript relate to a stress or strain either in the same (3) direction or in an orthogonal direction (1 or 2$)$.

Finally, another electromechanical data, the piezoelectric coupling factor $k$ (referred also as electromechanical coupling factor), is a convenient and direct measurement of the ability of the piezoelectric material to convert one form of energy to another. It is defined in equation 3 as follow:

$$
k=\sqrt{\frac{\text { mechanical energy stored }}{\text { electrical energy applied }}}=\sqrt{\frac{\text { electrical energy stored }}{\text { mechanical energy applied }}}<1 \quad \text { (Eq. 3) }
$$

Ways to calculate this electromechanical coupling coefficient in different piezoelectric resonators will be shown later.

In general, any material of a given size and shape has a natural resonant frequency at which it will vibrate, when a mechanical force put it at its resonant frequency. Then, because of damping forces, this vibration movement will stop. This of course happens for piezoelectric materials but, due to electromechanical coupling, these materials can be also electrically stimulated to produce vibrations at many frequencies. If the selected operating frequency is adjusted to mechanical resonance, large resonating strain is generated. Most devices are operated below resonance but the resonant operation can be used to make vibratory devices such as clocks or ultrasonic motors. When the piezoelectric body is stimulated by alternating fields or stresses at frequency close to the mechanical resonance, the piezoelectric resonator can be replaced by a equivalent electric circuit showing a mechanical (acoustic) component and an electric component connected in parallel (Fig. 4a). In this circuit, the motional branch $R_{M} L_{M} C_{M}$ models the mechanical resonance, whereas the capacitance $C_{0}$ in parallel to the resistor $R_{0}$ represents the dielectric with losses. The parallel combination of $R_{M}, L_{M}, C_{M}, C_{0}$ and $R_{0}$ 
dictates the impedance or admittance of the resonator showing maximum and minimum frequencies often merged with the resonance $f_{r}$ and anti-resonance frequencies $f_{a}$ (Fig. 4b). Thanks to these frequency measurements, the effective electromechanical coefficient $k_{\text {eff, }}$ is frequently used to characterize an arbitrary resonator at any resonance frequency (fundamental or harmonic) and is expressed as follow:

$$
k_{e f f}=\sqrt{\frac{\left(f_{a}^{2}-f_{r}^{2}\right)}{f_{r}^{2}}}(\text { Eq.4) }
$$

Also, by using suitably shaped and oriented piezoelectric, thanks to the electrical measurements (ie. impedance $Z$ or admittance $Y$ completed with dielectric measurements), the material constants can be calculated according to IEEE criteria (IEEE standard). For these measurements, the usually vibration modes studied are length - extensional modes of bar, radial and thickness modes of disks. For instance in rectangular plates or cylinder rods, through $f_{a}$ and $f_{r}$ resonant measurements, the piezoelectric coupling factor which is a direct measurement of the overall strength of the electromechanical effect can be calculated from equations 5 and 6 :

$$
\begin{aligned}
& k_{33}=\sqrt{\frac{\pi}{2} \frac{\mathrm{f}_{\mathrm{r}}}{\mathrm{f}_{\mathrm{a}}} \tan \left(\frac{\pi}{2} \frac{\mathrm{f}_{\mathrm{a}}-\mathrm{f}_{\mathrm{r}}}{\mathrm{f}_{\mathrm{a}}}\right)} \text { (longitudinal length mode of cylindar rods) (Eq. 5) } \\
& k_{31}=\sqrt{\frac{\frac{\pi f a}{2 f_{r}} \tan \left(\frac{\pi f a-f_{r}}{2 f_{a}}\right)}{1+\frac{\pi f a}{2 f_{r}} \tan \left(\frac{\pi f a-f_{r}}{2 f_{a}}\right)}} \text { (transverse length mode rectangular plates) (Eq. 6) }
\end{aligned}
$$

Also, Young's modulus $Y$ can be obtained by the relation:

$$
Y=\frac{1}{4 \rho L^{2} f_{r}^{2}} \text { (transverse length mode rectangular plates of length } L \text { and density } \rho \text { ) (Eq. 7) }
$$
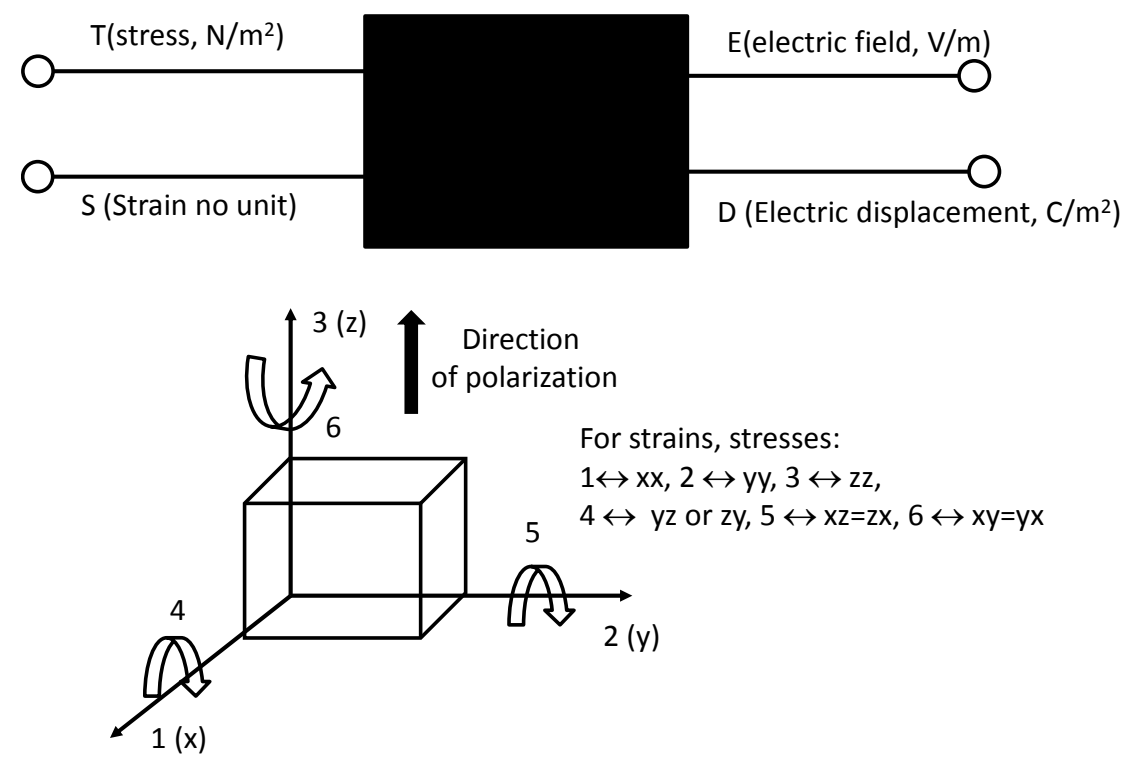

Figure 3: a) Four pole theory for electromechanical coupling b) Notations of axes 


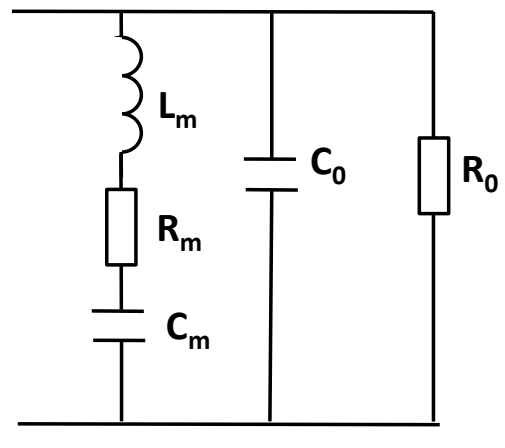

a)

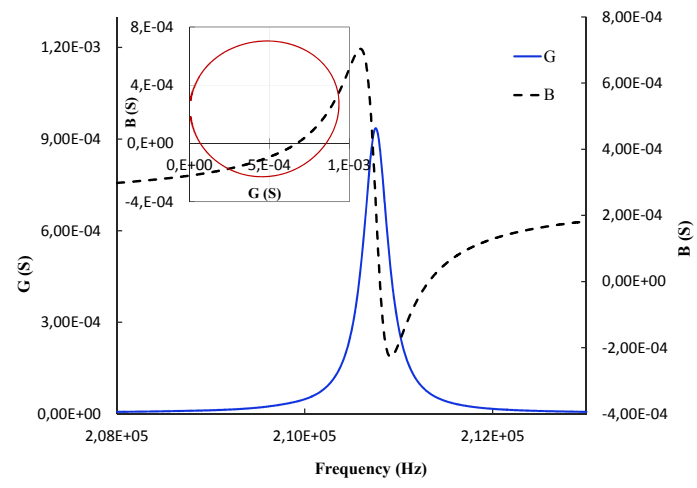

b)

Figure 4: Piezoelectric resonator a) equivalent circuit at resonance b) Example of conductance $G$ and susceptance $B$ as a function of the frequency $f$ measured for a PZT ceramic (insert with the $B(G)$ circle).

More details on the theory on piezoelectric theory can be found in Cady, 1946.

\section{II.2. Vibration energy harvester structure}

The electrical energy required to provide unlimited energy for electronic devices can be obtained by capturing sunlight, mechanical energy, thermal energy, and RF energy. Even if harvesting solar energy is nowadays the most efficient technology (typically tens of $\mathrm{mW} / \mathrm{cm}^{3}$ ), it cannot be used in the absence of light. We are here interested in harvesting mechanical energy of ambient or biomechanical vibrations because it can provide reasonable amount of energy (typically hundreds of $\mu \mathrm{W} / \mathrm{cm}^{3}$ ), sufficient to power wireless sensors (Roundy et al. 2003). Vibration is moreover a form of kinetic energy that can be easily found in many applications such as power tools, machinery, vehicles, etc. Human motion can also be used in portable electronic devices (Beeby et al, 2006).

A mechanical energy harvesting system aimed to capture vibration environmental energy traditionally comprises three elements as shown in the block diagram of figure $5 \mathrm{a}$ :

- the mechanical-mechanical converter that captures the energy. This best suited capture device is a mechanical oscillator with a proof (or seismic) mass (Beeby 2015).

- the energy converting transducer; the energy is usually transferred to the transducer with the proof mass. Note that the mechanical-mechanical converter and the transducer can be in some systems a single element.

- the electronic circuit to power the electronic load .

Electromagnetic, electrostatic or piezoelectric are the three main employed transduction methods. The piezoelectric approach is the most attractive among these three methods because it exhibits high energy density, its configuration is simple and there no need of a separate voltage source (Gilbert and Balouchi, 2008, Kausar et al. 2014). In this case, the piezoelectric transducer material is usually part of the spring of the mechanical oscillator.

For piezoelectric generators, the basic method consists in applying the strain in the same direction as the electric field ( 3 direction), it is the so called longitudinal configuration, using the $d_{33}$ mode 
(Fig. 5b) (Graton et al. 2013). But this method is not suitable for energy harvester mainly because of limited strain due to high stiffness, and high frequency operation. The transverse operation is hence preferred. For this configuration utilizing the $d_{31}$ mode, a typical piezoelectric energy harvester is a unimorph or bimorph cantilever where electroded piezoelectric films or ceramics are bonded onto the cantilever substrate. With a different electrode arrangement ie. interdigitated electrodes, the system benefits from the greater $d_{33}$ coefficient (Fig. 5c) (Lee et al. 2009).

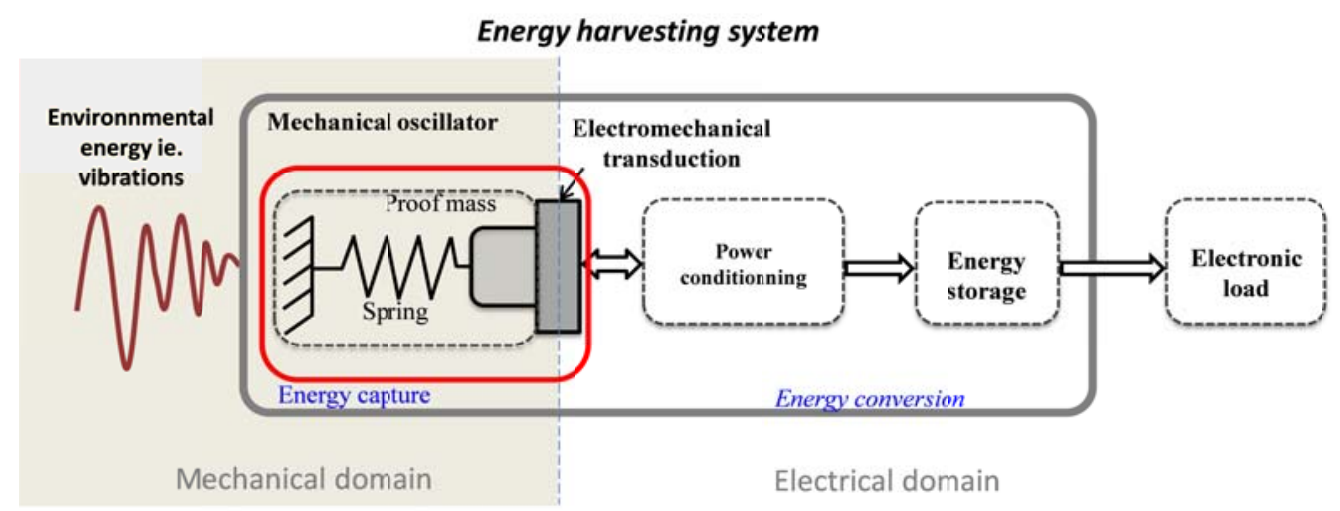

a)

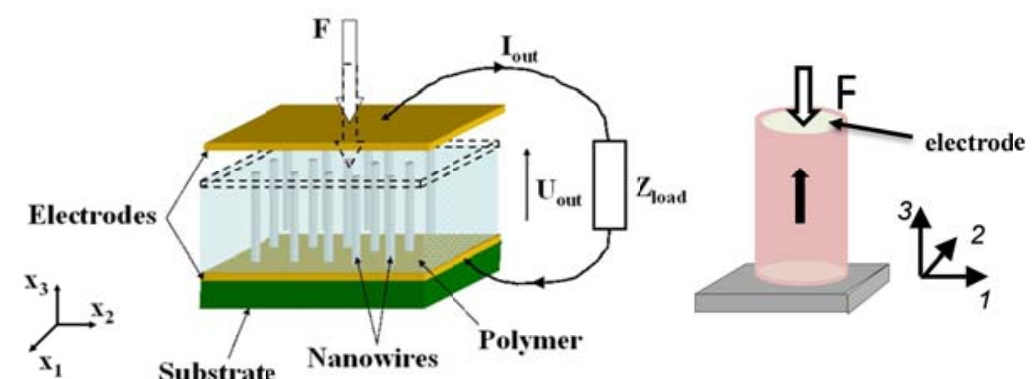

A nanowire under compressive force

b)

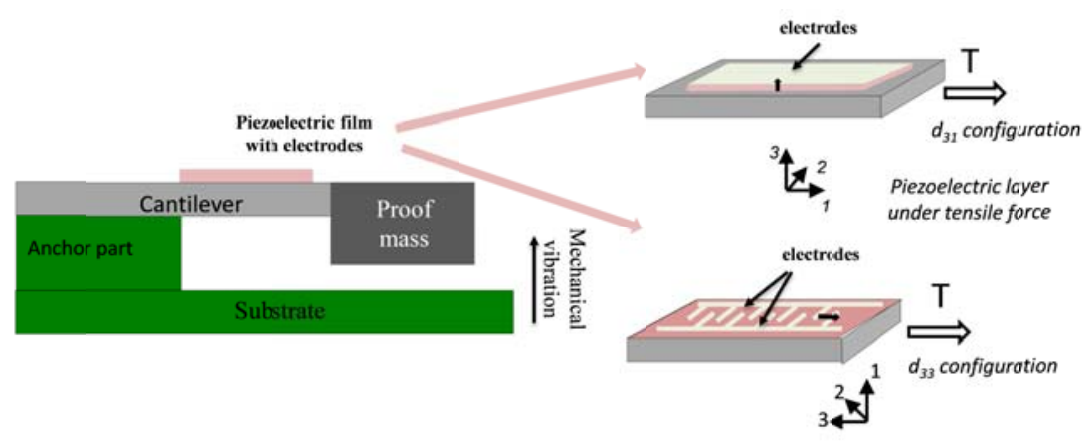

c)

Figure 5: a) Block diagram of a mechanical energy harvesting system and (b-c) typical configurations for piezoelectric transducers for energy harvesting using $d_{33}$ mode or $d_{31}$ modes (Graton et al. 2013 and Lee et al. 2009) 


\section{II.3 Piezoelectric materials requirements for energy harvesting}

In addition to the optimized design of the micro-energy haverster transferring the energy, the selection of the piezoelectric material needs also to be considered. Even if the electromechanical coupling coefficient indicating the energy conversion ability is a good criteria to choose the piezoelectric material, the figure of merit (FOM) (Roundy et al. 2003, Elfrink et al. 2009) should be taken into account to compare different materials for energy harvesting applications. This FOM applicable for materials, but not for devices, is defined as the electrical energy density divided by the mechanical deformations:

$$
F O M=\frac{d^{2} Y^{2}}{\varepsilon}=\frac{e^{2}}{\varepsilon}(\text { Eq.8) }
$$

Where $d$ is the piezoelectric strain coefficient, $Y$ is the elastic modulus, $\varepsilon$ the permittivity and $e$ is the piezoelectric stress coefficient.

Some properties of common piezoelectric materials used in energy harvesting (ceramics or films) and the corresponding calculated FOM are given Table 1. In this table, we can notice that AlN thin film appears to be more interesting than PZT thin film for energy harvesting MEMS, because of its good compatibility with microelectronic process. In addition, its reduced permittivity helps to increase its FOM despite its lower piezoelectric properties. It can be hence a good choice for MEMS piezoelectric energy harvester. To get a high FOM, a compromise can be found considering both permittivity values and piezoelectric performances. As an illustration, the FOM of PZT ceramics can be tuned according to the composition and thus the properties. Undoped PZT is rarely used for applications. A range of properties can be obtained by acceptor or donor doping on $\mathrm{A}$ and/or $\mathrm{B}$ sites of the perovskite $\mathrm{ABO}_{3}$. Acceptor-doped PZT $\left(\mathrm{K}^{+}, \mathrm{Fe}^{3+}, ..\right)$ are called "hard" PZT due to compensating defects (oxygen vacancies) that stabilize the domain structure which in turn becomes difficult to be reoriented (difficult poling). Donor doped PZT $\left(\mathrm{La}^{3+}, \mathrm{Nb}^{5+}, ..\right)$, on the contrary are compensated by electrons or lead vacancies and are easy to pole. They are called "soft", exhibiting high piezoelectric coefficients, high permittivity and dielectric losses (Damjanovic D., 1998). According to the targeted applications (sensors, actuators, etc...), hard or soft PZT may be selected. In table 1, the lower permittivity of hard piezoelectric PZT (PZ26) compared to the one of soft piezoelectric PZT (PZT-5H), compensates its lower piezoelectric coefficient $d$ allowing thus an increase of the FOM. 


\begin{tabular}{|c|c|c|c|c|c|c|c|c|c|}
\hline & & $\begin{array}{l}d_{33} \\
\left(p C . N^{-1}\right)\end{array}$ & $\begin{array}{l}-d_{31} \\
\left(p C N^{-1}\right)\end{array}$ & $k_{33}$ & $k_{31}$ & $\begin{array}{l}Y \\
(G P a)\end{array}$ & $\varepsilon$ & FOM & $\begin{array}{l}\text { Refe- } \\
\text { rences }\end{array}$ \\
\hline \multirow[t]{3}{*}{ Ceramics } & $\begin{array}{ll}\text { PZT } & 5 \mathrm{H} \\
\text { soft } & \\
\text { PZT } & 26 \\
\text { hard } & \end{array}$ & 650 & 130 & $\begin{array}{l}0.75 \\
0.68 \\
\end{array}$ & 0.44 & $\begin{array}{l}50 \\
20 \\
\end{array}$ & $\begin{array}{l}3400-3800 \\
1300\end{array}$ & $\begin{array}{l}0.075 \\
0.052 \\
\end{array}$ & $\begin{array}{l}\text { Beeby et } \\
\text { al. } 2015 \text {, } \\
(* 1) \text { and } \\
(* 2)\end{array}$ \\
\hline & $\mathrm{BaTiO}_{3}$ & $86 / 170$ & 35 & & 0.21 & & 1700 & 0.009 & $\begin{array}{l}\text { Beeby } \\
2015 \\
\text { Defay } 2015\end{array}$ \\
\hline & $\mathrm{KNN}$ & $80 / 160$ & & & & & $235-605$ & & $\begin{array}{l}\text { Quignon } \\
2013 / \\
\text { Gao, } 2016\end{array}$ \\
\hline \multirow[t]{4}{*}{$\begin{array}{l}\text { Thin } \\
\text { films }\end{array}$} & $\mathrm{PZT}$ & $\begin{array}{l}60-130 / \\
300\end{array}$ & $/ 120$ & & & & $\begin{array}{l}300-1300 / \\
1620 \\
/ 1000\end{array}$ & $\begin{array}{l}0.06- \\
0.14\end{array}$ & $\begin{array}{l}\text { Ledermann } \\
2003 \\
\text { Calame } \\
\text { 2007/ } \\
\text { Beeby } \\
2015 \\
\end{array}$ \\
\hline & $\mathrm{KNN}$ & 42 & & & & & $258-930$ & & $\begin{array}{l}\text { Quignon } \\
\text { 2013/ } \\
\text { Kanno } \\
2018 \\
\end{array}$ \\
\hline & AlN & 5 & $1.5 / 2.5$ & $-/ 0.07$ & $\begin{array}{l}0.065 \\
/-\end{array}$ & $-/ 300$ & 10 & 0.20 & $\begin{array}{l}\text { Beeby et al. } \\
2015 / \\
\text { Defay et al. } \\
2015\end{array}$ \\
\hline & $\mathrm{ZnO}$ & 5.9 & & & 0.074 & 209 & 10.9 & 0,14 & $\begin{array}{l}\text { Carlotti } \\
1987\end{array}$ \\
\hline \multirow[t]{3}{*}{$\begin{array}{l}\text { Thick } \\
\text { films }\end{array}$} & $\begin{array}{l}\text { PZT } \\
\text { (aerosol) }\end{array}$ & & 17 & & & & & & Lin 2013 \\
\hline & $\begin{array}{l}\text { PZT } \\
\text { (screen- } \\
\text { printed) }\end{array}$ & - & 89 & - & - & - & 829 & & Xu 2012 \\
\hline & PVDF & -33 & 23 & & 0.15 & & 12 & $\begin{array}{l}0.000 \\
5\end{array}$ & $\begin{array}{l}\text { Beeby } \\
2015\end{array}$ \\
\hline
\end{tabular}

Table 1: Comparison of FOM of typical piezoelectric material used for energy harvesting application $\left({ }^{* 1}\right)$ https://support.piezo.com/article/62-material-properties\#msds (*2) https:// https://www.meggittferroperm.com/wp-content/uploads/2017/10/MSSDK_PZ26_Datasheet201809.pdf and https://fr.scribd.com/document/72129499/Ferroperm-Catalogue

Typical energy harvesters are Silicon based MEMS fabricated by micromachining where the piezoelectric material is deposited by thin film processes. With this technology, EHs present reduced size and are promising. The proof mass is in silicon, and PZT, ZnO or AlN thin films are common materials (Elfrink et al. 2009, Jeon et al. 2005, Shen el al. 2008, Wang et al. 2015). 
The choice of the materials (active piezoelectric material or passive substrate), the design of the EH and the process nevertheless depend on the required performances for a given application (frequency, acceleration, required power) and of the costs. Alternative processes can be thus proposed. In particular thicker piezoelectric layers combined with flexible substrates (for instance metallic substrates) may be nowadays preferred to achieve higher power. In the next paragraph, because our proposed multilayer EH is based on a metallic substrate with PZT thick film, examples of EH using metallic substrates and PZT thick films are shown.

\section{II.4 Examples of piezoelectric vibration EH}

A typical piezoelectric mechanical energy harvester is a straight beam with a seismic mass at the end. More complicated structures can also be used in order to decrease the resonant frequency such as spiral, zig-zag or meandering (Paprotny et al. 2010, Fernandes et al 2018, Monin et al, 2016, Berdy et al. 2012).

Common piezoelectric EH are millimeter size cantilevers, unimorph or bimorph with two pieces of bulk piezoelectric material sandwiching a metallic stainless substrate (Roundy and Wright, 2004). Thinning of the bulk bonded ceramic are moreover proposed to bridge the 1 to $100 \mu \mathrm{m}$ gap which lies between bulk and thin film components Once thinned, these bulk ceramics can be micro-structured on metallic supports (Colin et al. 2013), but also on silicon substrates as reported by Aktakka et al.2011. With a bimorph harvester with a $50 \mu \mathrm{m}$ PZT layer of thinned bulk ceramic reported on a stainless substrate (Fig. 6a), Colin et al measured $3 \mu \mathrm{W}$ a very low frequency $(15 \mathrm{~Hz})$ and under $10 \mathrm{mg}$, demonstrating the efficiency of such piezoelectric energy scavengers.

But these processes require additional micromachining, grinding and/or polishing of the bulk ceramics which needs finally to be manually assembled. An interesting alternative is the use of thick film processes to fabricate the PZT transducer (screen-printing, sol-gel process, electrophoretic deposition, tape-casting or aerosol deposition). For instance, screen-printed piezoelectric thick-films implemented on stainless steel platforms have been shown to deliver power of $\sim 240 \mu \mathrm{W}$ harvested at $66.2 \mathrm{~Hz}$ with an acceleration of $g=2.8 \mathrm{~m} . \mathrm{s}^{-2}(0.3 \mathrm{~g})$ (Zhu et al. 2011). With the same acceleration, free-standing piezoelectric thick-films (bimorph structure) fabricated on a silicon sacrificial substrate (Xu et al. 2012 ) provide $\sim 3 \mu \mathrm{W}$ at $250 \mathrm{~Hz}$ though power of $\sim 50 \mu \mathrm{W}$ is measured at $242 \mathrm{~Hz}$ for $\mathrm{g}=13.7 \mathrm{~m} . \mathrm{s}^{-2}(1.4 \mathrm{~g})$. Figure $6 \mathrm{~b}$ shows the different harvested powers under acceleration varying from $0.2 \mathrm{~g}$ to $1.4 \mathrm{~g}$. Here, even with an additional high pressure step (100-200MPa) before the sintering 1 hour at $850^{\circ} \mathrm{C}$, the screen-printed PZT layers show average apparent porosity of $20 \%$. Stainless steel substrate is so far the most popular metallic substrate because for its relatively low Young's modulus. But other metallic substrates are also studied as brass, copper, nickel or aluminum (Bai et al. 2015, Yeo et al. 2018, Monin et al. 2016).

Performances of some selected vibration piezoelectric EH can be compared in table 2. The authors attempt herein to give different kind of technologies that can be used, from the materials and their processing (piezoelectric layer, substrate, proof mass), the dimensions of the EH to their performances under vibration. Here, it is worth noting the comparison is complex because of many parameters influencing the total harvester powers. The normalized power in W. $\mathrm{m}^{-3} \cdot \mathrm{g}^{-}{ }^{2}$ (Tang et al. 2018) is often proposed for a fair comparison of the intrinsic properties of the EH. 


\begin{tabular}{|c|c|c|c|c|c|}
\hline Multilayer / proof mass & $\begin{array}{l}\text { Deposition piezoelectric } \\
\text { layer technology }\end{array}$ & EH volume & $\begin{array}{l}\text { Frequency/ } \\
\text { acceleration } \\
\left(1 \mathrm{~g}=9.8 \mathrm{~m} / \mathrm{s}^{2}\right)\end{array}$ & Power & References \\
\hline $\begin{array}{l}\text { Bimorph } \quad \mathrm{PZT} / 100 \mu \mathrm{m} \\
\text { brass } / \mathrm{PZT} / / \text { Tungsten proof mass } \\
9.15 \mathrm{~g}\end{array}$ & PZT-5H Bulk $-280 \mu \mathrm{m}$ & $1 \mathrm{~cm}^{3}$ & $120 \mathrm{~Hz} / 0.25 \mathrm{~g}$ & $375 \mu \mathrm{W}$ & Roundy 2004 \\
\hline $\begin{array}{l}\text { PZTAuIn } / 10 \mu \mathrm{mSi} \quad / / \text { Tungsten } \\
\text { proof mass } 328 \mathrm{mg}\end{array}$ & Thinned bulk PZT $20 \mu \mathrm{m}$ & $7 \times 7 \times 0,55 \mathrm{~mm}^{3}$ & $154 \mathrm{~Hz} / 1.5 \mathrm{~g}$ & $205 \mu \mathrm{W}$ & Aktakka 2011 \\
\hline $\begin{array}{l}\text { Bimorph } \\
\text { Ag/PZT/Au/dielectric/110 } \mu \mathrm{mSS} / \\
\text { dielectric/Au/PZT/Ag // Tungsten } \\
\text { proof mass } 3.1 \mathrm{~g}\end{array}$ & $\begin{array}{l}\text { Screen-printed } \quad \text { PZT-5H / } \\
70 \mu \mathrm{m}\end{array}$ & $491 \mathrm{~mm}^{3}$ & $67 \mathrm{~Hz} / 0,4 \mathrm{~g}$ & $240 \mu \mathrm{W}$ & Zhu 2011 \\
\hline $\begin{array}{l}\text { Bimorph/TiPt/PZT/TiPt/PZT/Au } \\
\text { // Tungsten proof mass Si }\end{array}$ & $\begin{array}{l}\text { Screen-printed PZT (PZ26) } \\
20 \mu \mathrm{m}\end{array}$ & $0.64 \mathrm{~mm}^{3}$ & $242 \mathrm{~Hz} / 1 \mathrm{~g}$ & $33.2 \mu \mathrm{W}$ & Xu 2012 \\
\hline $\begin{array}{l}\mathrm{SUS304} / \mathrm{Pt} / \mathrm{Ti} / \mathrm{PZT} / \mathrm{Al} / / \quad \text { not } \\
\text { reported }\end{array}$ & Sol gel PZT thin film $4 \mu \mathrm{m}$ & $167.6 \mathrm{~mm}^{3}$ & $89 \mathrm{~Hz} / 1 \mathrm{~g}$ & $15 \mu \mathrm{W}$ & Wang 2012 \\
\hline $\begin{array}{l}\text { Bimorph PZT/ } \text { Stainless steel } \\
15 \mu \mathrm{m} / \mathrm{PZT} / / \text { Tungsten proof } \\
\text { mass } 1.5 \mathrm{~g}\end{array}$ & Thinned bulk PZT $50 \mu \mathrm{m}$ & $\begin{array}{l}5 \times 40 \mathrm{~mm}^{2} \times \\
115 \mu \mathrm{m}\end{array}$ & $16 \mathrm{~Hz} / 10 \mathrm{mg}$ & $3 \mu \mathrm{W}$ & Colin 2013 \\
\hline $\begin{array}{l}\mathrm{Pt} / \mathrm{Ti} / \mathrm{PZT} / \mathrm{SS} 30 \mu \mathrm{m} / / \quad \text { Tungsten } \\
\text { proof mass } 6 \mathrm{x} 4 \mathrm{x} 0,45 \mathrm{~mm}^{3}(0.2 \mathrm{~g})\end{array}$ & Aerosol deposition $15 \mu \mathrm{m}$ & $\begin{array}{l}8 \quad \mathrm{x} \quad 6 \mathrm{~mm}^{2} \\
\times 45 \mu \mathrm{m}\end{array}$ & $112.4 \mathrm{~Hz} / 1.5 \mathrm{~g}$ & $200 \mu \mathrm{W}$ & Lin 2013 \\
\hline $\begin{array}{l}\mathrm{SS} 300 \mu \mathrm{m} / \mathrm{Pt} / \mathrm{Ti} / \mathrm{KNN} / \mathrm{Pt} / / \quad \mathrm{SS} \\
\text { proof mass } 25 \mathrm{mg}\end{array}$ & $\begin{array}{l}\text { KNN RF Sputtering } 2.2 \mu \mathrm{m} \\
\text { PZT RF Sputtering - }\end{array}$ & $\begin{array}{c}7.5 \times 5 \mathrm{~mm}^{2} \\
\times 2.2 \mu \mathrm{m}\end{array}$ & $\begin{array}{l}393 \mathrm{~Hz} / 1 \mathrm{~g} \\
367 \mathrm{~Hz} / 1 \mathrm{~g}\end{array}$ & $\begin{array}{l}1.6 \mu \mathrm{W} \\
6.7 \mu \mathrm{W}\end{array}$ & Tsujiura 2013 \\
\hline $\begin{array}{l}\text { Bimorph PtTi/PZT/PtTi } \\
\mathrm{SS} 60 \mu \mathrm{m} / \mathrm{PtTi} / \mathrm{PZT} / \mathrm{PtTi} / / \\
\text { Tungsten proof mass } 0.46 \mathrm{~g}\end{array}$ & Aerosol deposition $10 \mu \mathrm{m}$ & $\begin{array}{l}6 \mathrm{x} 8 \mathrm{~mm}^{2} \mathrm{x} \\
80 \mu \mathrm{m}\end{array}$ & $120 \mathrm{~Hz} / 0,5 \mathrm{~g}$ & $304 \mu \mathrm{W}$ & Tang 2018 \\
\hline $\begin{array}{l}\mathrm{Ni} 25 \mu \mathrm{m} / \mathrm{LaNiO}_{3} / \mathrm{HfO}_{2} / \mathrm{Ni} / / \mathrm{PZT} \\
/ \mathrm{Pt} / / \text { Brass proof mass } 0.4 \mathrm{~g}\end{array}$ & PZT RF Sputtering $3 \mu \mathrm{m}$ & $0.1155 \mathrm{~mm}^{3}$ & $72 \mathrm{~Hz} / 0,5 \mathrm{~g}$ & $60 \mu \mathrm{W}$ & Yeo 2018 \\
\hline
\end{tabular}

Table 2: Examples of performances of resonant piezoelectric energy harvester cantilever types using different technologies 


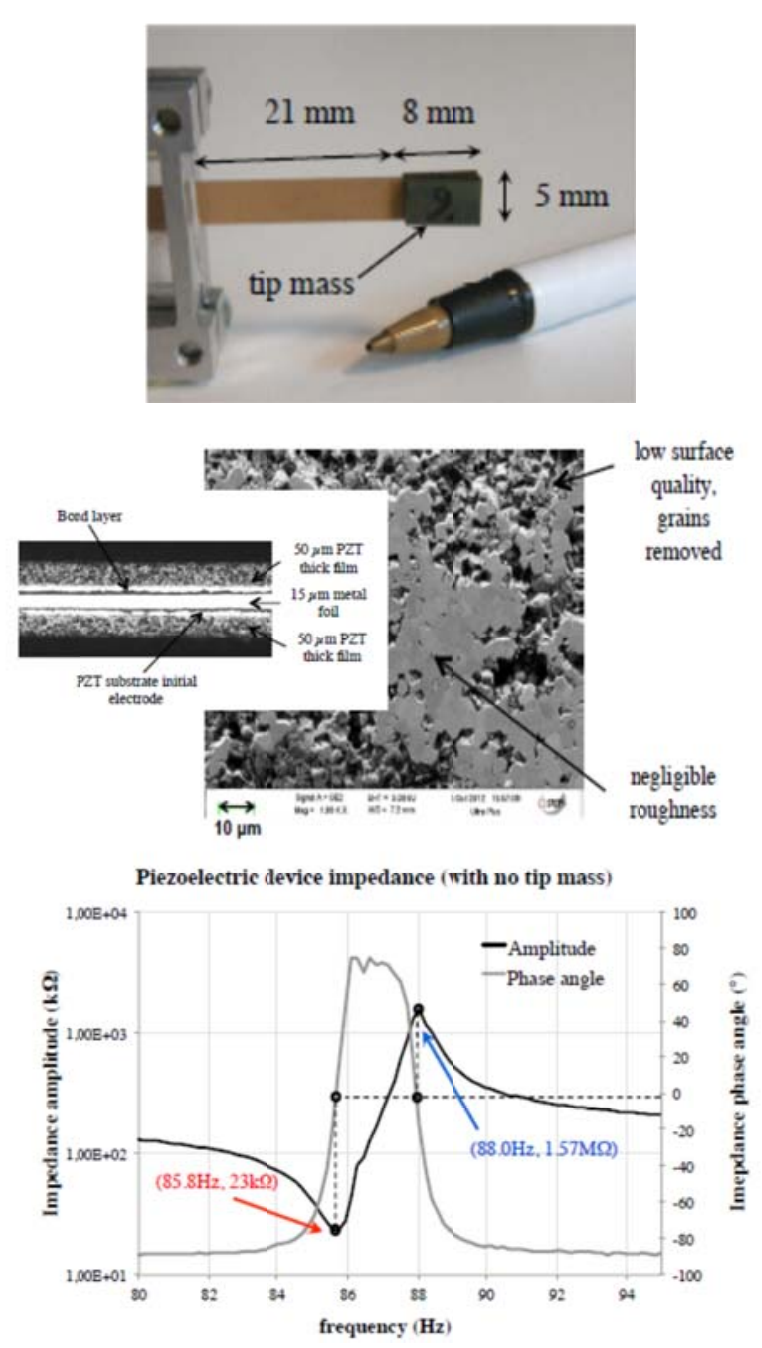

a)
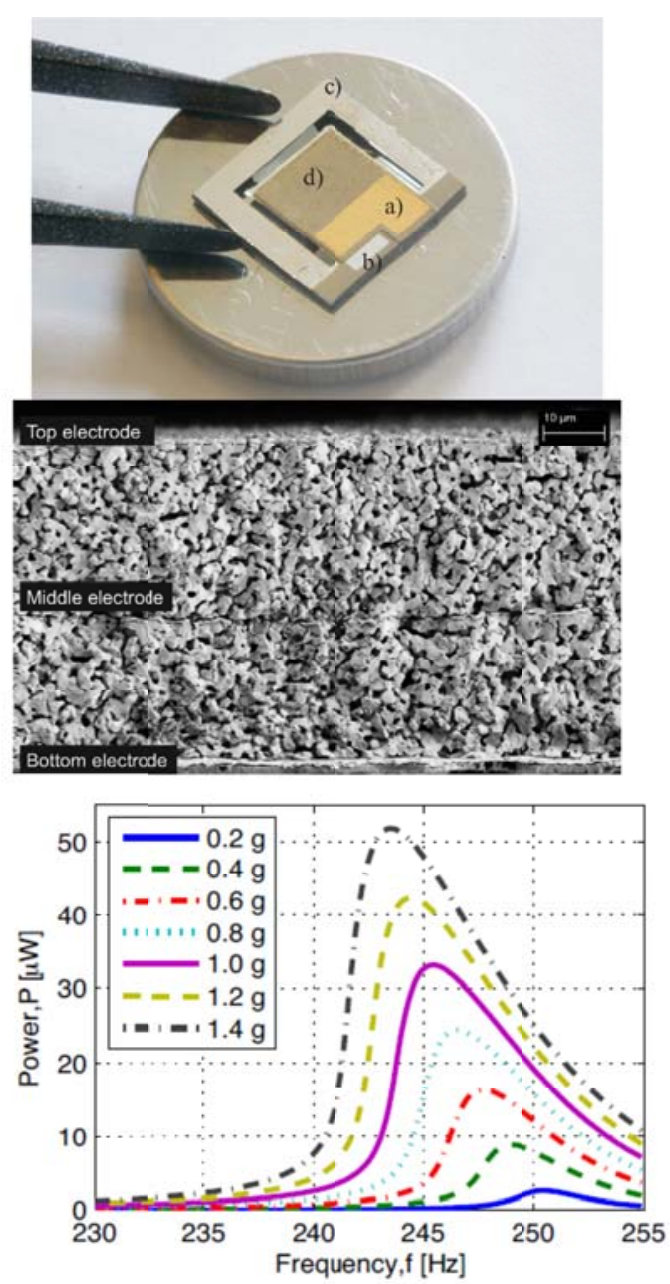

b)

Figure 6: Examples of bimorph piezoelectric vibration energy harvesters $(\mathrm{EH})$, photograph, microstructure and electrical characterization a) thinned bulk PZT assembled on SS substrate (Colin et al. 2013) b) screen-printed PZT EH (Xu et al. 2012)

\section{Conventional approach for the screen-printed piezoelectric energy harvester}

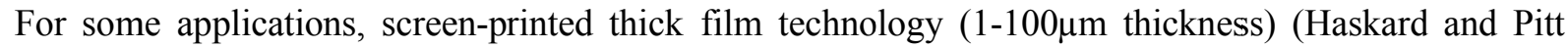
1997) might lead to lower cost than traditional ceramic process for PZT-MEMS manufacturing (no needs for slicing and polishing piezoelectric ceramics prior to electrodes deposition). For actuation or vibration energy harvesting purpose, thick films process is moreover attractive to reach piezoelectric thick-film layers to maximize the electromechanical coupling (Hindrichsen et al. 2010). Here, as in numerous works (see table 1) a stainless steel (SS301 type 250 $\mu \mathrm{m}$ thick) is selected for processing of a printed energy harvester, because of it low Young's modulus compared to alumina classically used in thick film technology, or to silicon wafers. This substrate moreover withstands the high firing temperature necessary for the densification of the printed PZT layers. Piezoelectric MEMS thick-film fabrication steps are typically undertaken sequentially, starting from the paste formulation and screenprinting, followed by drying, co-firing and finally polarization. 
Our EH microsystem consists in a three-dimensional thick-film structure made of a thick PZT layer sandwiched between two gold electrodes deposited on a stainless substrate (SS). The PZT powder is a commercial hard type PZT26 from Ferroperm. This powder is mixed with the eutectic 3\%wt phase $\mathrm{LBCu}\left(\mathrm{Li}_{2} \mathrm{CO}_{3} \mathrm{Bi}_{2} \mathrm{O}_{3} \mathrm{CuO}\right)$ instead of borosilicate glasses, for a better reproducibility, and densification at low temperature, as shown in previous work (Debéda et al. 2015). The piezoelectric paste is prepared with the PZT: LBCu powder blended with an organic commercial binder (ESL400 from Electroscience Laboratory). The weight percentage is optimized to have adapted viscosity for printing. More details can be found in Debéda et al. 2015. For the fabrication of the piezoelectric EH, Au, PZT and $\mathrm{Au}$ layers are subsequently screen-printed on the SS substrate, with a drying step at $120^{\circ} \mathrm{C}$ between each deposition (Fig. 7 a). A simple cantilever for vibration energy harvesting and a specific zig-zag shaping optimized in a previous work for piezoelectromagnetic transduction have been fabricated (Fernandes et al. 2018) (Fig. 7c). After printing, the layers are isostatically pressed at $40 \mathrm{MPa}$ during 5 minutes at $65^{\circ} \mathrm{C}$ before the co-firing of all the layers at $900{ }^{\circ} \mathrm{C}(2 \mathrm{~h})$, in air. The pressure step, combined with the addition of the eutectic phase improves the densification (Debéda et al. 2005, Xu et al. 2005). As shown on figure $7 \mathrm{~b}$, the final PZT fired thickness is approximately $50 \mu \mathrm{m}$ and the porosity of the PZT printed on SS substrates evaluated by using ImageJ analysis software is around $24 \%$. The interface between the substrate and the bottom gold electrode reveals also a $20 \mu \mathrm{m}$ adhesion layer. As detailed in Rua-Taborda et al. (submitted in Ceramics International), in our complex multilayer EH, as in other multilayers, interdiffusion between all the stacked layers and expansion thermal coefficient mismatch can lead to bending of the structure and reduced performances of the piezoelectric material (Gao et al., 2016). Even with slight bending of the structures, the multilayer could be polarized at $250 \mathrm{~V}$ under nitrogen and just below the Curie temperature. After this last step, this cantilever was shown to be promising for smart grid applications as shown in Fernandes et al. 2018 and Yang et al 2018. Piezoelectric factor $d_{31}$ of $40 \mathrm{pC} / \mathrm{N}$ were used for finite element modelling conducted on piezoelectric energy harvester.

(a)

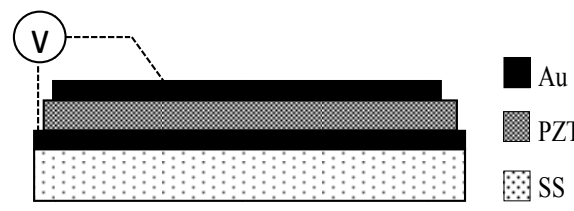

(c)

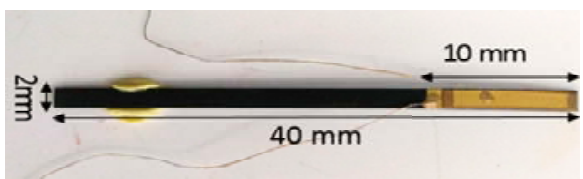

(b)

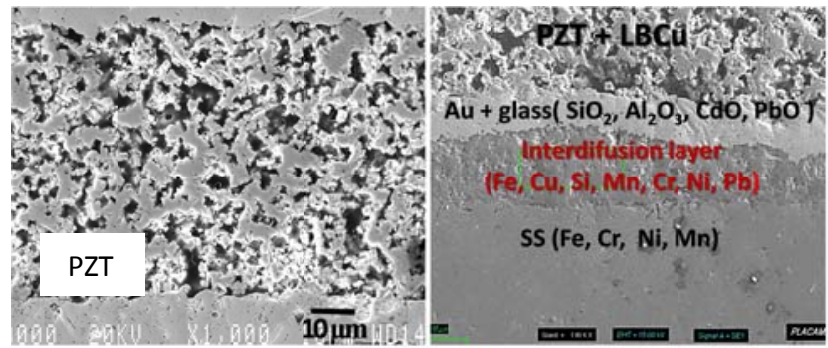

(d)

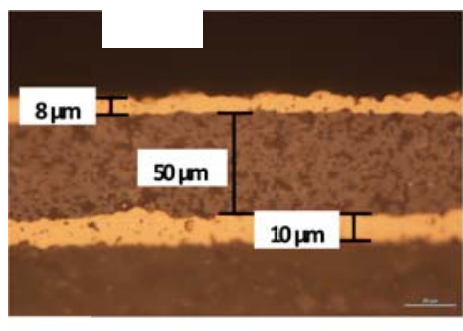

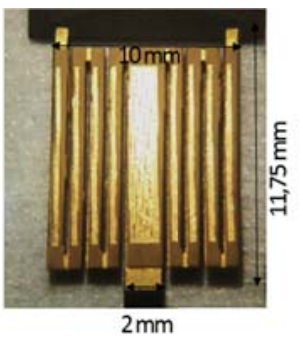

Figure 7: (a) Scheme of the layers stacking (b) SEM cross section of the interfaces (c-d) Photographs of the SS/Au/PZT/Au cantilevers and zig-zag type (Fernandes et al. 2018) 


\section{New densification route by SPS of metallic supported printed multilayer for PZT piezoelectric energy harvesting}

PZT based energy harvester is a complex multimaterial whose fabrication raises multiple issues related to (i) the control of the chemistry and microstructure (non-stoichiometry and volatility of elements, grain size) and (ii) the control of interfaces (interdiffusion, thermal expansion mismatch between ceramic and metals leading to delamination and bending). These features strongly impact properties such as electrical breakdown strength, electrical conductivity, piezoelectric strain as well as charge and ferroelectric switching. Thanks to various sintering aids such as LBCu (Debéda et al.2005 ), $\mathrm{LiBiO}_{2}+\mathrm{CuO}$ (Wang et al. 2001) or $\mathrm{Li}_{2} \mathrm{CO}_{3}+\mathrm{PbO}$ (Donnelly et al. 2009) the sintering temperature of thick film and PZT based ceramics was efficiently lowered $\left(\sim 900^{\circ} \mathrm{C}\right)$ compared to conventionally sintered commercial PZT $\left(\mathrm{T}>1200^{\circ} \mathrm{C}\right)$. However the chemistry at the grain boundaries remains hardly controlled and the densification not always optimized.

The trend towards lower energy consumption while keeping optimum reliability requires an optimization of the sintering stage decreasing the sintering temperature, limiting the number of thermal treatments and controlling the chemistry according to the sintering environment. Such an optimization is mandatory when processing complex devices such as printed PZT thick films integrated in MEMS, for which the co-sintering with metals remains challenging. In this context, the use of advanced sintering process such as Spark Plasma Sintering appears as a relevant approach given its specificities: fast kinetics, lower temperatures and short sintering times.

\section{IV1.2. PZT ceramics sintered by SPS}

\section{IV1.2.1 State of the art}

A review of literature shows that sintering of PZT and related solid solutions by SPS is performed under low oxygen partial pressure at temperatures that usually remain higher than $900^{\circ} \mathrm{C}$ (Table 3). A post-annealing treatment under air is generally mandatory to eliminate oxygen vacancies and recover insulating properties. It is required to control the oxygen vacancies as they may play an important role in the fatigue process under electric field (Damjanovic, 1998). This post thermal treatment performed in the range $700-1100{ }^{\circ} \mathrm{C}$, is a key step to control charged defects and, more generally defect chemistry at the grain boundaries (Legallais et al. 2018). In particular, space charge accumulation at the grain boundaries can significantly alter the poling process (reorientation of domains) and contribute to the conductivity and dielectric losses. The defect concentration and their spatial distribution depends on both the sintering temperature and the sintering technique, and can be modified during post annealing.

The efficiency of SPS with regards to conventional sintering can hardly be properly evaluated as the dielectric and piezoelectric properties are not systematically reported and when provided they concern different initial compositions and various microstructures in terms of grain size. However it is worth noting that most of the studies use SPS at temperatures lower or similar than the ones used for 
conventional sintering of screen-printed thick films. The dwell time $\left(\sim 5^{\prime}\right)$ is also drastically reduced compared to conventional approaches for which several hours are required to achieve high density. An additional significant advantage lies in the absence of sintering aids. The main drawback rests on the post SPS annealing step at temperatures similar or even higher than the sintering temperature. Such post -treatment weighs on the global thermal budget limiting thus the gain of energy efficiency provided by fast sintering at low temperature. In this context, our approach, described in the next section, includes the use of the same commercial PZT powder as for conventional process (section III) and focuses on the investigation of SPS with as a main goal to avoid the post sintering annealing step. Our strategy is built on the use of a protective layer powder deposited directly on the top of the PZT bed powder. The use of insulating disks or thermal buffers during SPS was reported in literature. These thermal and electrical barriers allow to reduce the heat conduction and to control current distribution across punch/die/powder assembly (limited current leakage). They can be located either directly at the contact of the powder or between the rams and punches (S. Grasso et al. 2009). Alumina powders were also used to prevent ferroelectric ceramics from chemical reduction during SPS sintering (Elissalde et al, 2018) and to prevent the pistons of deforming copper spiral extremities in SPS co-sintering of transformers for power electronics (Mercier et al. 2016).

In order to optimize the SPS sintering not only for PZT ceramics but also in the perspective of the sintering of the multilayer ( $\mathrm{Au} / \mathrm{PZT} / \mathrm{Au} /$ stainless steel), our specifications for the protective layer must meet multiple criteria: to protect PZT from the chemical reduction without hindering a good densification, to be inert at the selected sintering temperature in order not to interact chemically with PZT but also with gold in the case of the multilayer, to be removed easily by polishing or etching without altering the material in contact. We have selected $\mathrm{SrCO}_{3}$ which meets all expectations, and has also proved to be very effective as a sacrificial layer in the fabrication of the released screen-printed thick films (Debéda et al. 2015, Rua-Taborda et al. submitted in J. Eur. Ceram. Soc.). The microstructure and electrical properties of PZT ceramics performed by SPS with and without $\mathrm{SrCO}_{3}$ are here investigated and compared. Their performances are also confronted to conventionally sintered commercial ceramics and screen-printed thick films. 


\begin{tabular}{|c|c|c|c|c|c|c|c|}
\hline Material & $\begin{array}{l}\text { Sintering } \\
\text { Temperature } \\
\text { (heating rate) }\end{array}$ & $\begin{array}{l}\text { Holding } \\
\text { Time } \\
(\min )\end{array}$ & $\begin{array}{l}\text { Pressure } \\
\text { (MPa) }\end{array}$ & $\begin{array}{l}\text { Post thermal } \\
\text { treatment }\end{array}$ & $\begin{array}{l}\text { Density } \\
\left(\mathrm{g} / \mathrm{cm}^{3}\right)\end{array}$ & $\begin{array}{l}\text { Electrical } \\
\text { Properties }\end{array}$ & $\begin{array}{l}\text { Refe- } \\
\text { rences }\end{array}$ \\
\hline $\begin{array}{l}\mathrm{PbZrO}_{3}-\mathrm{PbTiO}_{3} \\
\mathrm{~Pb}\left(\mathrm{Zn}_{1 / 3} \mathrm{Nb}_{2 / 3}\right) \mathrm{O}_{3}\end{array}$ & $\begin{array}{l}\mathbf{9 0 0}^{\circ} \mathrm{C} \\
\left(100^{\circ} \mathrm{C} / \mathrm{min}-\right. \\
800^{\circ} \mathrm{C} \text { and } \\
33 \quad{ }^{\circ} \mathrm{C} / \mathrm{min} \quad- \\
\left.900^{\circ} \mathrm{C}\right)\end{array}$ & 10 & 29 & $\begin{array}{l}\text { Ih at } 900^{\circ} \mathrm{C} \\
\text { In a } \mathrm{PbO}-\text {-rich } \\
\text { atmosphere }\end{array}$ & 7.95 & Not reported & $\begin{array}{l}\mathrm{Wu} \\
2002 \mathrm{a}\end{array}$ \\
\hline $\begin{array}{l}\mathrm{Pb}(\mathrm{Zr} 0.53 \mathrm{Ti} 0.47) \mathrm{O}_{3}- \\
1 \% \mathrm{Nb}\end{array}$ & $\begin{array}{l}\mathbf{1 0 0 0}^{\circ} \mathbf{C} \\
\left(100^{\circ} \mathrm{C} / \mathrm{min}\right)\end{array}$ & $\begin{array}{l}0,1,2, \\
\text { and } 4\end{array}$ & 50 & $3 \mathrm{~h}$ at $1000^{\circ} \mathrm{C}$ & 7.95 & Not reported & $\begin{array}{l}\text { Chinen } \\
2011\end{array}$ \\
\hline $\mathrm{Pb}\left(\mathrm{Zr} 0.3 \mathrm{Ti}_{0.7}\right) \mathrm{O}_{3}$ & $\begin{array}{l}\mathbf{9 0 0}^{\circ} \mathrm{C} \\
\left(100^{\circ} \mathrm{C} / \mathrm{min}-\right. \\
800^{\circ} \mathrm{C} \text { and } \\
33 \quad{ }^{\circ} \mathrm{C} / \mathrm{min} \quad- \\
\left.900^{\circ} \mathrm{C}\right)\end{array}$ & 5 & 29 & lh at $1100^{\circ} \mathrm{C}$ & 7.80 & $\begin{array}{l}\varepsilon<500 \\
\left(25^{\circ} \mathrm{C}\right)\end{array}$ & $\begin{array}{l}\mathrm{Wu} \\
2002 b\end{array}$ \\
\hline $\begin{array}{l}\mathrm{Pb}\left(\mathrm{Zr}_{0.52} \mathrm{Ti}_{0.42} \mathrm{Sn}_{0.02}\right. \\
\left.\mathrm{Nb}_{0.04}\right) \mathrm{O}_{3} \\
\text { Grain size < } \\
500 \mathrm{~nm}\end{array}$ & $\begin{array}{l}1050^{\circ} \mathrm{C} \\
\left(100^{\circ} \mathrm{C} / \mathrm{min}\right)\end{array}$ & 5 & 50 & $\begin{array}{l}4 \mathrm{~h} \text { at } 700^{\circ} \mathrm{C} \\
\text { under air }+ \\
6 \mathrm{~h} \text { at } 1000^{\circ} \mathrm{C}\end{array}$ & 7.64 & $\begin{array}{l}\mathrm{d}_{33} \sim 330 \\
\mathrm{pm} / \mathrm{V} \\
\left(25^{\circ} \mathrm{C}\right)\end{array}$ & $\begin{array}{l}\text { Han } \\
2017\end{array}$ \\
\hline $\begin{array}{l}\mathrm{Pb}(\mathrm{Zr} 0.53 \mathrm{Ti} 0.47) \mathrm{O}_{3}- \\
1 \% \mathrm{Nb}_{2} \mathrm{O}_{5} \\
\text { Grain size } 330 \mathrm{~nm}\end{array}$ & $\begin{array}{l}\mathbf{1 0 0 0}^{\circ} \mathbf{C} \\
\left(120^{\circ} \mathrm{C} / \mathrm{min}\right)\end{array}$ & 1 & 50 & Not reported & $\begin{array}{l}\text { Not } \\
\text { reported }\end{array}$ & $\begin{array}{l}\varepsilon \approx 920 \\
\left(25^{\circ} \mathrm{C}\right) \\
\mathrm{d}_{33} \sim 180 \\
\mathrm{pC} / \mathrm{N}\end{array}$ & $\begin{array}{l}\text { Ochoa } \\
2018\end{array}$ \\
\hline $\begin{array}{l}\text { PMN-PZT } \\
\text { Grain size } 1 \mu \mathrm{m}\end{array}$ & $\begin{array}{l}\mathbf{9 8 0}^{\circ} \mathbf{C} \\
\left(100^{\circ} \mathrm{C} / \mathrm{min}\right)\end{array}$ & 5 & 50 & $850^{\circ} \mathrm{C} 12 \mathrm{~h}$ & $\begin{array}{l}\text { Not } \\
\text { reported }\end{array}$ & $\begin{array}{l}\varepsilon \approx 6000 \\
\left(25^{\circ} \mathrm{C}\right) \\
\mathrm{d}_{33^{3}} \sim 400 \\
\mathrm{pm} / \mathrm{V}\end{array}$ & $\begin{array}{l}\text { Chen } \\
2018\end{array}$ \\
\hline $\begin{array}{l}\text { Reference: PZ26 } \\
\text { conventional } \\
\text { sintering }\end{array}$ & $1200^{\circ} \mathrm{C}$ & $\begin{array}{l}\text { Not } \\
\text { reported }\end{array}$ & & & $\begin{array}{l}7.7 \\
\text { (relative } \\
\text { density } \\
99 \% \text { ) }\end{array}$ & $\begin{array}{l}\varepsilon \approx 6000 \\
\mathrm{~d}_{33} \sim 290 \\
\mathrm{pC} / \mathrm{N}\end{array}$ & $\begin{array}{l}\text { Ferro- } \\
\text { perm }\end{array}$ \\
\hline
\end{tabular}

Table 3: Some properties and process conditions of PZT based ceramics densified by SPS

IV1.2.2 Protective layer based approach

Spark plasma sintering is performed using an SPS apparatus Syntex Inc., SPS-515S. PZT powder without sintering aid is loaded in a cylindrical graphite die with an inner diameter of $10 \mathrm{~mm}$ and heated under low oxygen partial pressure. The temperature is raised at $50{ }^{\circ} \mathrm{C} / \mathrm{min}$ and kept at a constant value in between 800 and $875^{\circ} \mathrm{C}$ for $5 \mathrm{~min}$. A constant pressure of $50 \mathrm{MPa}$ is applied along the Z-axis of the graphite die during the whole sintering process. The SPS samples performed without $\mathrm{SrCO}_{3}$ protective layer are annealed in air at $800{ }^{\circ} \mathrm{C}$ for $10 \mathrm{~h}$ in order to remove surface carbon contamination and to 
limit oxygen vacancies caused by the reducing conditions. When the protective layer is used, the removal of $\mathrm{SrCO}_{3}$ after sintering is ensured by either polishing or chemical etching in phosphoric acid prior microstructural and electrical characterizations.

a) Comparison of PZT ceramics densified by SPS without and with protective layer

The microstructures of PZT sintered at 800 and $875^{\circ} \mathrm{C}$, without $\mathrm{SrCO}_{3}$ and after subsequent reoxidation (annealing $10 \mathrm{~h}$ at $800^{\circ} \mathrm{C}$ ) are shown on Figure 8. Sintering at the lowest temperature leads to poor densification with a relative density of $68 \%$. An increase in the sintering temperature of only $50^{\circ} \mathrm{C}$ allows a significant increase in densification, reaching $\sim 95 \%$.Open porosities are nevertheless observed and the grain size increases from the range $500 \mathrm{~nm}-1 \mu \mathrm{m}$ to $1-2 \mu \mathrm{m}$. The best density is finally obtained at $875^{\circ} \mathrm{C}$ with $\sim 98 \%$ of relative density. Larger grain size in the range $2-4 \mu \mathrm{m}$ is observed (Fig. 8). It is worth noting that SPS allows to efficiently densify PZT at temperature lower than $900^{\circ} \mathrm{C}$ without any additives. Density and microstructure of the SPS ceramics are comparable to those of conventionally sintered commercial ceramics at $1200^{\circ} \mathrm{C}$ (www.meggittferroperm.com). Referring to the SPS studies reported in table 3, although the sintering temperature of $875^{\circ} \mathrm{C}$ is slightly lower, density remains comparable. In terms of grain size, the comparison cannot be rigorous given the lack of information or because of very different compositions.
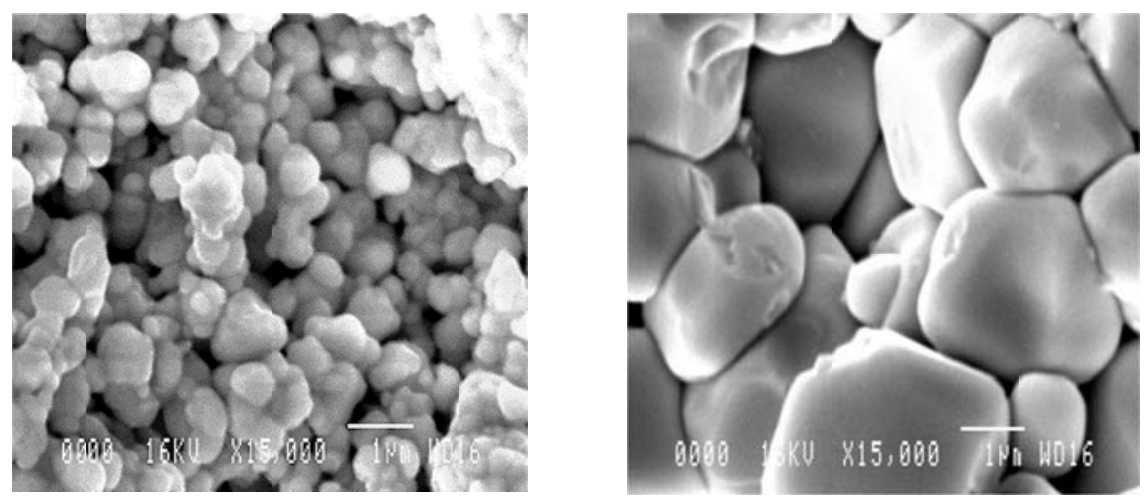

Figure.8: SEM images of PZT ceramics densified by SPS at $800^{\circ} \mathrm{C}$ (left) and at $875^{\circ} \mathrm{C}$ (right)

The gain in densification achieved at $875^{\circ} \mathrm{C}$ compared to 800 and $850^{\circ} \mathrm{C}$ may give better electromechanical properties. Prior to these electrical measurements, sputtered $\mathrm{Au}$ electrodes are deposited on the disks before the polarization step at $\approx 400 \mathrm{~V} / \mathrm{mm}$. On figure 9 , impedance modulus and phase as a function of the frequency are reported for the planar vibration mode of the electroded disks. The results obtained at $800^{\circ} \mathrm{C}$ are not displayed due to their low electromechanical response. On the reported curves, resonant and anti-resonant frequencies appear to be in the interval $210-240 \mathrm{kHz}$. Differences of few tens of $\mathrm{kHz}$ are attributed to slightly diameter changes $( \pm 2 \mathrm{~mm})$, induced during the disks preparation (polishing). The bests electromechanical properties are clearly observed for the

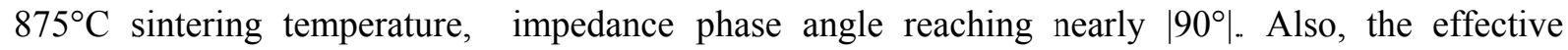
coupling factor $k_{\text {eff }}$ (Eq. 4 ) is evaluated to $30 \%$ for this temperature, whereas it hardly reaches $20 \%$ for the sintering temperature of $850^{\circ} \mathrm{C}$, confirming that highest density are benefit for piezoelectric properties. In case of thick films fabricated by conventional process, the value of $k_{\text {eff }}$ was only $11.5 \%$ due to porosity $(\sim 20 \%)$. 

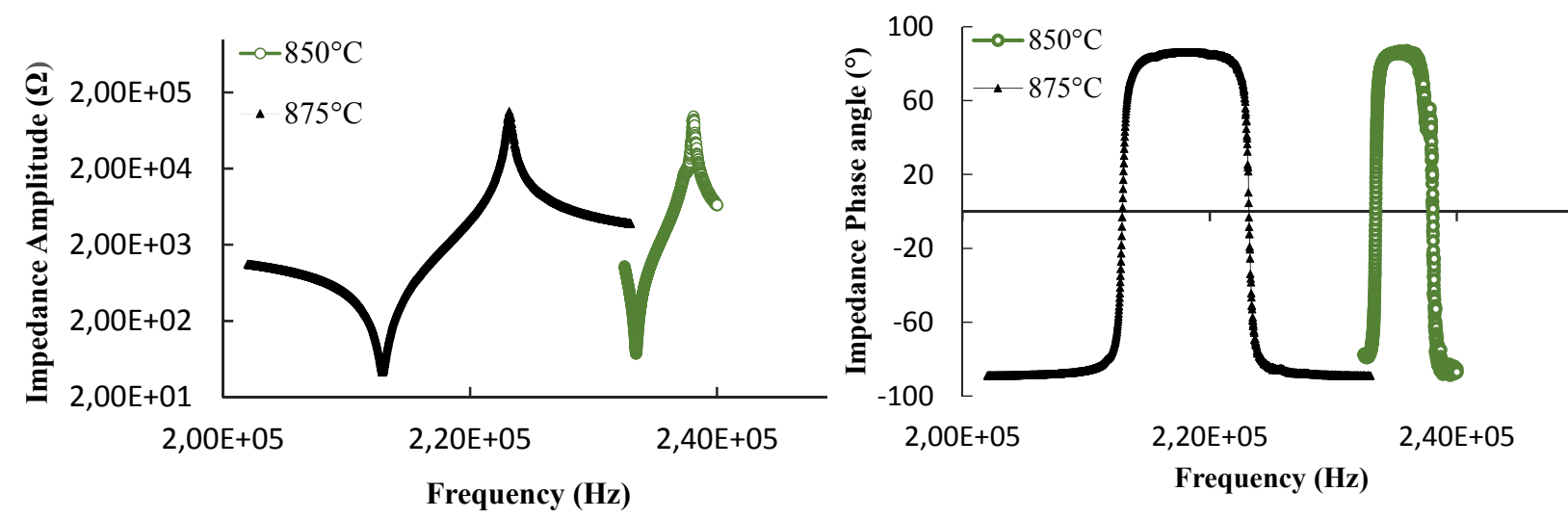

Figure 9: Impedance amplitude and phase measured for ceramics sintered by SPS at different temperatures (no $\mathrm{SrCO}_{3}$ coating)

The optimal sintering temperature of $875^{\circ} \mathrm{C}$ is thus selected for SPS experiments using the protective $\mathrm{SrCO}_{3}$ layer. SEM image of the ceramic after removal of $\mathrm{SrCO}_{3}$ reveals highly densified ceramic $(\sim 98 \%)$ with an average grain size similar to the one of PZT without $\mathrm{SrCO}_{3}$ meaning that the protective layer does not affect the densification (Fig. 10). The ceramic exhibits a perovskite type structure with predominantly tetragonal phase at room temperature in agreement with the initial composition and without signature of secondary phase (XRD not shown) (Rua-Taborda et al. submitted in J. Eur. Ceram. Soc. 2019).

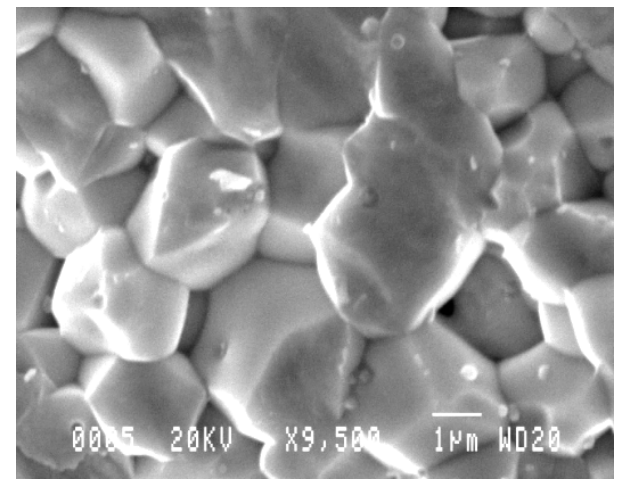

Figure 10: SEM image of PZT sintered by SPS using a $\mathrm{SrCO}_{3}$ protective layer

In order to prove the efficiency of the protective layer against reduction, electrical measurements were led directly after sintering and etching of $\mathrm{SrCO}_{3}$. Dielectric characterizations performed as a function of temperature and in the frequency range $100 \mathrm{~Hz}-100 \mathrm{kHz}$ are shown on Figure 11. The Curie temperature (Tc) corresponding to the maximum of permittivity is located at $330^{\circ} \mathrm{C}$ as expected for the PZ26 composition (www.meggittferroperm.com). The room temperature permittivity reaches 1500, a value higher than the one reported for this commercial powder $\left(\varepsilon \approx 1300-\right.$ sintering at $\left.1200^{\circ} \mathrm{C}\right)$ and much more higher than the one reported by Wu et al. $2002 \mathrm{~b}\left(\varepsilon<500\right.$ sintering at $900^{\circ} \mathrm{C}+$ annealing $1 \mathrm{~h}$ at $1100^{\circ} \mathrm{C}$ ). A slight frequency dispersion of the permittivity can be observed in the vicinity of the Curie temperature but there is no signature of conductivity (increase in permittivity) at high temperature $\left(\mathrm{T}>400^{\circ} \mathrm{C}\right)$. The permittivity at $\mathrm{Tc}$ and at $1 \mathrm{kHz}$ reaches a value as high as 19800 reflecting the high quality of the ceramic. The room temperature dielectric loss $(\tan \delta)$ is lower than $1 \%$ and remains stable as a function of temperature up to $350^{\circ} \mathrm{C}$ (insert Fig. 11). The observed increase of $\tan \delta$ 
from $380^{\circ} \mathrm{C}$ at the lowest frequencies $(<1 \mathrm{kHz})$ netherveless reflects the existence of residual space charges. However, the obtained dielectric characteristics, comparable or even better than those of commercial ceramics, attest to the quality of the grain boundaries and confirm the efficient role of the protective layer. In such conditions, SPS without subsequent annealing allows to obtain in one step high quality piezoelectric ceramics exhibiting performant properties.

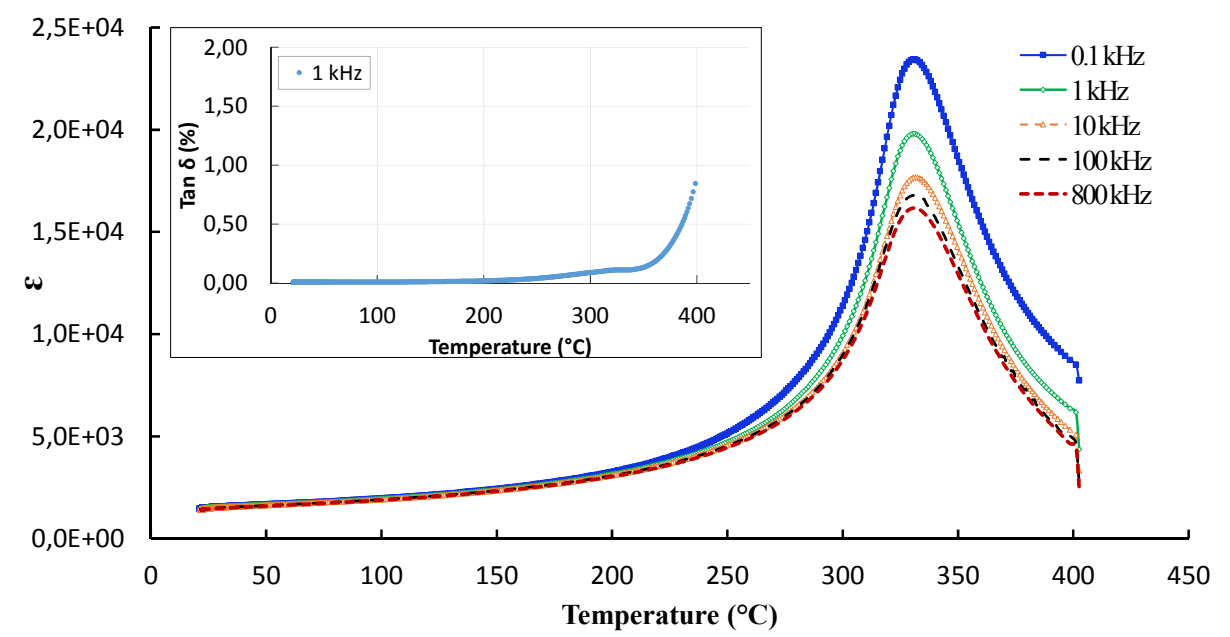

Figure 11: Thermal variation of the permittivity at different frequencies for $\mathrm{PZT} / \mathrm{SrCO}_{3}$ sintered by SPS (no reoxidation) - Insert: Dielectric losses as a function of $\mathrm{T}$ at $1 \mathrm{kHz}$.

An additional proof that the annealing is not here essential is the effective polarization of the ceramic directly after SPS. The poling process failed when PZT is densified without a protective layer due to the charges and associated leakage current, making the annealing prior poling process mandatory in this case. When using the protective layer, Au electroded PZT ceramics can be directly poled before their electromechanical characterization. The measured admittance $B(G)$ circle (B susceptance, $G$ conductance) of diameter $1 / R$ ( $R$ the resistance of the motional branch, see Fig. $4 \mathrm{~b}$ ) is clearly a proof of the piezoelectric effect (Fig.12a). Higher diameter of $B(G)$ circles reveal a better electromechanical coupling ie. lower mechanical energy losses by viscous damping effect. The disk sintered at $875^{\circ} \mathrm{C}$ with the $\mathrm{SrCO}_{3}$ protective gives clearly the best properties, larger diameter of $B(G)$ disk and highest $k_{\text {eff }}$ reaching $36.4 \%$ instead of $30 \%$ without $\mathrm{SrCO}_{3}$ (Fig. 12). These results clearly highlight the efficiency of the SPS sintering associated with the use of $\mathrm{SrCO}_{3}$.

\section{b) Comparison with conventional commercial ceramics and screen-printed thick films}

The microstructural and electromechanical properties of the screen-printed thick film, the commercial PZ26 ceramic and the SPS ceramics are summed up in table 4. These results show that, despite a reduced sintering temperature, $875^{\circ} \mathrm{C}$ instead of $900^{\circ} \mathrm{C}$ (screen-printed thick films ) or $1200^{\circ} \mathrm{C}$ (commercial ceramics), and the absence of additives, the electromechanical coupling factor is reaching a good value of $36 \%$. Nevertheless, it is still lower than for the commercial ceramic (50\%) probably because of not optimized polarization conditions. The comparison clearly highlights and demonstrates the potential of the SPS process for an efficient densification in one step thanks to the use of the $\mathrm{SrCO}_{3}$ protective layer. 


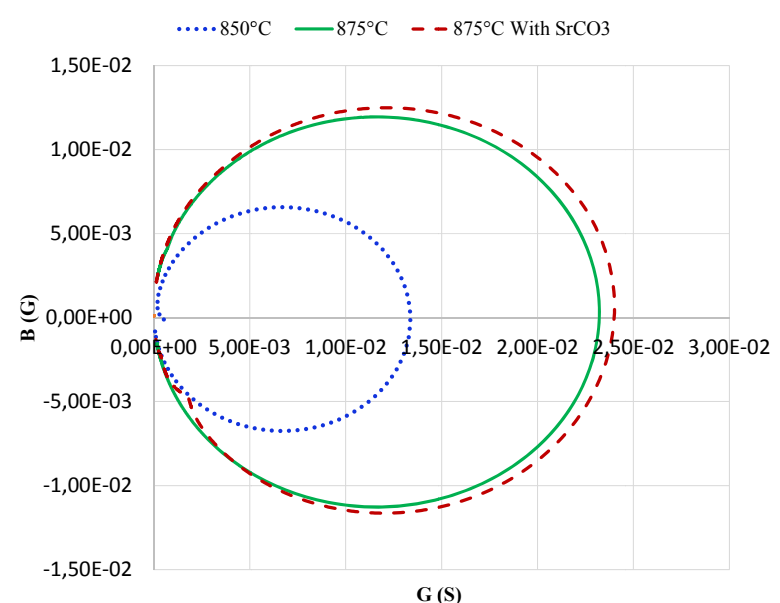

(a)

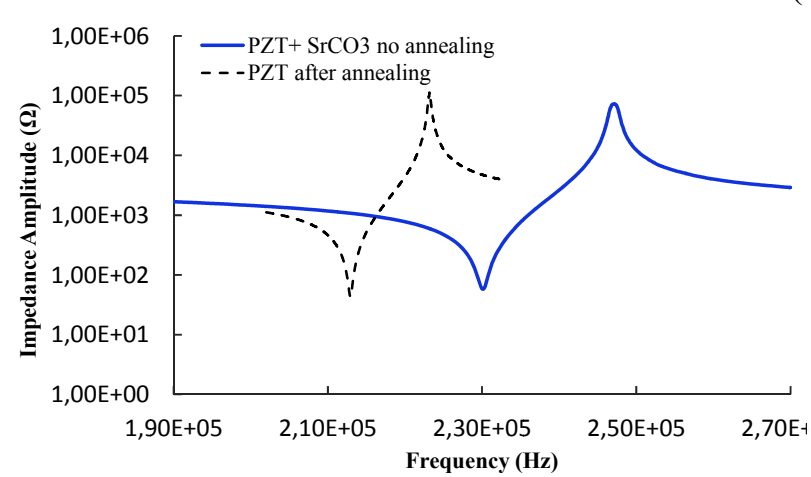

(b)

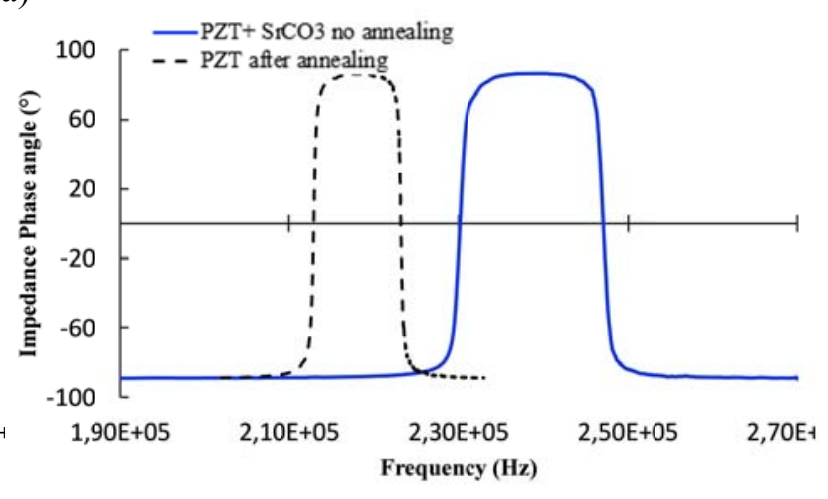

(c)

Figure 12: Electromechanical measurements for $\mathrm{PZT}+\mathrm{SrCO}_{3}$ sintered by SPS (no reoxidation) in contrast with samples with no protective layer and annealing post-treatment $-\left(800^{\circ} \mathrm{C} 10 \mathrm{~h}\right)(\mathrm{a})$ admittance $B(G)$ circle, impedance amplitude (b) and phase (c) for $\mathrm{PZT} / \mathrm{SrCO}_{3}$ (no reoxidation) and PZT(after annealing), both sintered by SPS at $875^{\circ} \mathrm{C}$

\begin{tabular}{|c|c|c|c|c|c|c|c|}
\hline & $\begin{array}{l}\text { Temperature } \\
\text { Holding time } \\
\text { Heating rate }\end{array}$ & $\begin{array}{l}\text { Pressure } \\
(\mathrm{MPa})\end{array}$ & Annealing & $\begin{array}{l}\text { Grain } \\
\text { size } \\
(\mu \mathrm{m})\end{array}$ & $\begin{array}{l}\text { Relative } \\
\text { density } \\
(\%)\end{array}$ & $\begin{array}{l}\mathrm{k}_{\mathrm{eff}} \\
(\%)\end{array}$ & $\varepsilon$ \\
\hline $\begin{array}{l}\text { Screen-printed } \\
\text { thick film } \\
\text { (sintering aid) }\end{array}$ & $\begin{array}{l}900^{\circ} \mathrm{C} \\
2 \mathrm{~h} \\
40^{\circ} \mathrm{C} / \mathrm{min}\end{array}$ & 40 & & $1-4$ & 82 & 11.5 & 330 \\
\hline SPS ceramic & $\begin{array}{l}875^{\circ} \mathrm{C} \\
5 \mathrm{~min} \\
50^{\circ} \mathrm{C} / \mathrm{min}\end{array}$ & 50 & $\begin{array}{l}\text { Post } \\
\text { annealing } 8 \mathrm{~h}, \\
800^{\circ} \mathrm{C}\end{array}$ & $2.5-4$ & 97.4 & 30 & 1164 \\
\hline $\begin{array}{l}\text { SPS ceramic + } \\
\text { protective layer }\end{array}$ & $\begin{array}{l}\mathbf{8 7 5}^{\circ} \mathbf{C} \\
5 \mathrm{~min} \\
50^{\circ} \mathrm{C} / \mathrm{min}\end{array}$ & 50 & No & $2.5-5$ & 98.2 & 36.4 & 1500 \\
\hline $\begin{array}{l}\text { Conventional } \\
\text { commercial } \\
\text { sintering } \\
\text { (Ferroperm) }\end{array}$ & $1200^{\circ} \mathrm{C}$ & - & & $2-5$ & 98.7 & 50 & 1300 \\
\hline
\end{tabular}

Table 4: Comparison of the properties of the PZ26 ceramics sintered by different methods 


\section{IV.2.2 SPS densification of the multilayer Au/PZT/Au/stainless steel}

\section{a) Metal/ceramic interfaces}

SPS is widely used for the assembly of materials and is recognized as an efficient sintering process for co-sintering or bonding. The control of chemistry and defects at interfaces is a key issue. If temperature and pressure contribute to mass transport enhancement, the influence of current through electromigration or defects concentration and mobility has also to be considered (Munir Z.A. et al. 2006). The current and/or temperature effects on the formation of interphases was mainly studied for multilayers intermetallic systems (Garay J.E et al 2003, Anselmi-Tamburini U. et al. 2005). The studies reported in literature dealing with ceramic/metal or metal/polymer multilayers assemblies concern to a large extent Functionnaly Graded Materials (FGM). (Tokita, 1999). Composites made of biocompatible ceramic and metal $\left(\mathrm{Al}_{2} \mathrm{O}_{3} / \mathrm{Ti}\right)$ were investigated by SPS in order to optimize the mechanical properties (Fujii T. et al 2016). It was shown through bending tests that fracture occurs within a reaction layer formed at the interface. Hardness and bending strength of the alumina-titanium composites were compared to those of FGM samples (Bahraminasab M et al. 2017). The reactivity of titatium with alumina and the presence of micro-cracks for SPS sintered $\mathrm{Al}_{2} \mathrm{O}_{3} / \mathrm{Ti}$ functionally graded materials was also reported by Madec C. et al 2018. Focusing on materials designed by SPS for electronic devices applied to energy harvesting, only few studies were reported. Issindou et al (2018) worked on simple SPS magnetostrictive ceramics optimized by SPS, but no multilayers were studied. $\mathrm{Cu} / \mathrm{PZT}$ functionally graded materials were fabricated by SPS targeting actuators applications (Fang M. et al, 2003). The impact of copper particles addition into PZT matrix on the dielectric properties and the electrical conductivity was investigated. Piezoelectric properties were not reported. In the case of multilayers stacking, monolithic transformers for power applications were co-sintered by Spark Plasma Sintering (Mercier et al. 2016). The reported transformer is made of two spiral copper coils, a dielectric layer and a spinel ferrite magnetic circuit. The advantages of SPS lies here on the reduced sintering temperature that allows to co-sinter copper with the ferrite powder and on the possibility to obtain a monolithic structure that eases the heat transfer from the coils. Deformation and leakage inductance issues were identified and were solved by adapting dimensions and sintering conditions (sintering aid). However the argon atmosphere during SPS was revealed as detrimental regarding to the ferrite resistivity. This study illustrates well several issues that must be tackled when using SPS to co-sinter complex structures. The SPS densification of the multilayer Au/PZT/Au/stainless steel remains challenging, we report in next section our approach to face some of the problems encountered and some perspectives of improvement.

\section{b) Our approach}

Same screen printing pastes as for the conventional process (section III) are used to deposit PZT on the SS substrate, the Au bottom and top electrodes. However the active PZT layer in sandwich between the two electrodes does not contain $\mathrm{LBCu}$. The protective layer $\mathrm{SrCO}_{3}$ is printed on the top $\mathrm{Au}$ electrode. After drying at $120^{\circ} \mathrm{C}$, the multilayer is thus directly sintered by SPS without any preliminary firing, debinding or pressure steps. The SPS sintering conditions optimized for PZT ceramics and discussed in the previous section have been transposed to some extent to sinter the multilayer. Heating ramp of $50^{\circ} \mathrm{C} / \mathrm{min}$ and a holding time of 5 minutes are maintained. Considering the multiple interfaces within the multilayer (top Au/PZT, PZT/bottom Au/SS), the sintering temperature is slightly decreased to $850^{\circ} \mathrm{C}$ in order to prevent interdiffusion (in particular from the glass frit contained in the gold paste) but is maintained sufficiently high to guarantee satisfactory densification. Experiments are performed by turn-off the temperature at the end of the plateau and letting the system cool naturally. Transient thermal gradients can induce stress gradients through the 
multilayer with as a result delamination issues. The most challenging aspect is here to avoid the delamination between the active PZT layer and the bottom gold electrode. Rapid cooling can affect the driving force for delamination. However controlling the cooling rate does not allow in this case to efficiently reduce the constraints. The pressure is another critical parameter in the case of multilayer. For the screen-printed film, a pressure of $40 \mathrm{MPa}\left(5 \mathrm{~min}\right.$ at $\left.65^{\circ} \mathrm{C}\right)$ applied prior sintering favors PZT densification and allows to reach a relative density of $82 \%$. The pressure of 50MPa applied during SPS of PZT ceramic enhances densification but obviously cannot be applied on the stack. Specific mold and carbon elements have been designed to ensure a uniform pressure applied on the stack (Fig.14).

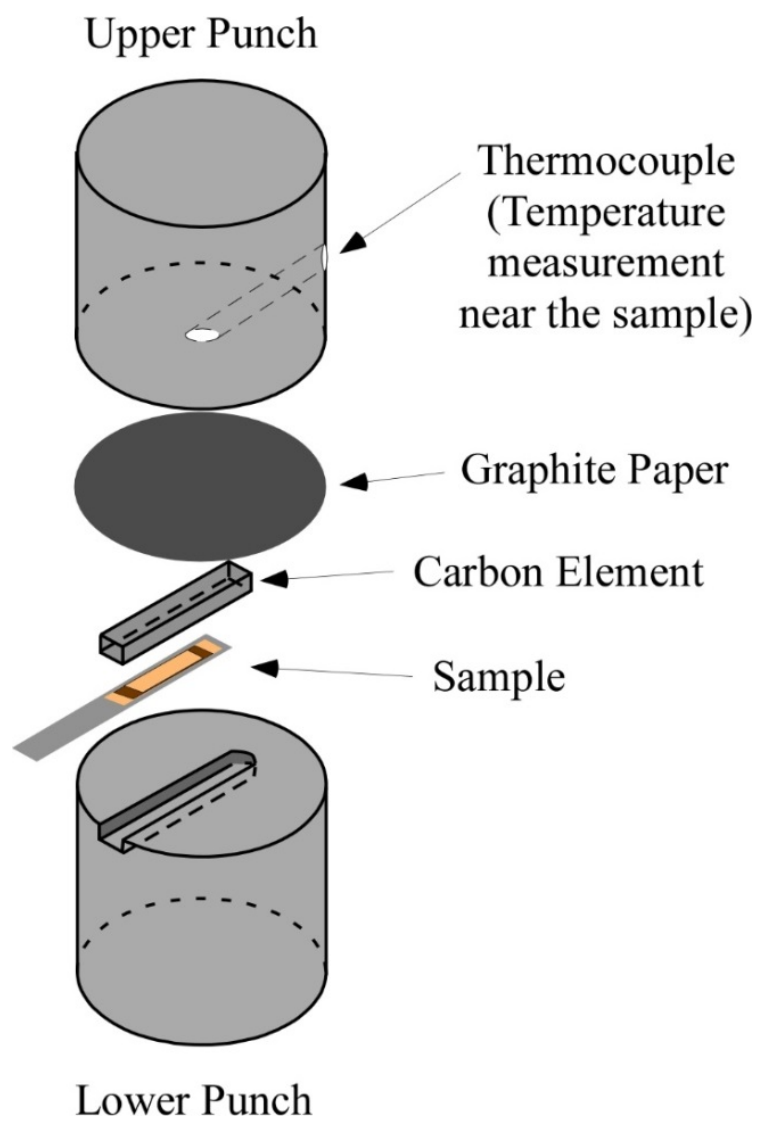

Fig. 14 Schematic drawn of the SPS mold designed for multilayer sintering

Figure 15 a) illustrates the printed $\mathrm{Au} / \mathrm{PZT} / \mathrm{Au} / \mathrm{SS}$ multilayer before sintering and before deposition of the $\mathrm{SrCO}_{3}$ layer. Because the top gold electrode does not recover entirely the active layer, the $\mathrm{SrCO}_{3}$ is then in contact with both PZT and Au. The selected low sintering temperature guarantees the absence of reaction at interfaces $\left(\mathrm{SrCO}_{3} / \mathrm{PZT}\right.$ and $\left.\mathrm{SrCO}_{3} / \mathrm{Au}\right)$ and is compatible with the formulation of the gold paste containing glass frit to ensure good adhesion with substrate. A zoom of the $\mathrm{Au} / \mathrm{PZT} / \mathrm{Au}$ is shown after SPS and removal of the protective layer (Fig.15b). The removal of the $\mathrm{SrCO}_{3}$ layer is another critical step because the integrity and good adhesion of all the layers are mandatory to be able to pole the sample prior electromechanical characterization. The bottom Au electrode and PZT are not damaged after etching process but the full removal of $\mathrm{SrCO}_{3}$ remains more challenging than for SPS ceramic. During the various tests aiming at improving the design of the mold, the weakest part of the assembly is the interface between the PZT and the bottom electrode leading to delamination (Fig.15c). 


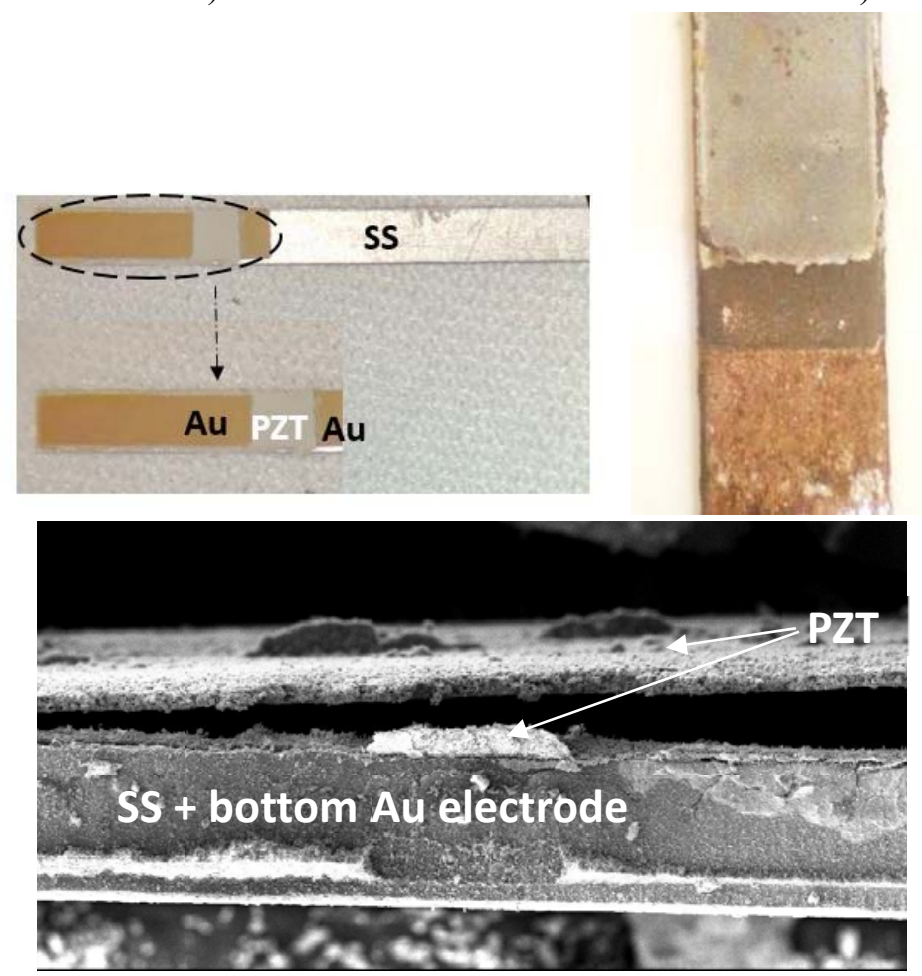

c)

Fig. 15: a) Photo of the printed $\mathrm{Au} / \mathrm{PZT} / \mathrm{Au} / \mathrm{SS}$ multilayer before sintering, b) Photo of the multilayer after SPS $\left(850^{\circ} \mathrm{C}-5^{\prime}\right)$ and removal of $\mathrm{SrCO}_{3}$, c) SEM image showing delamination between PZT and bottom gold electrode after sintering.

The microstructure of PZT within the stack has been characterized and compared to the one of the screen-printed PZT thick film conventionally sintered (Fig. 16). Very similar microstructures are obtained. Grain sizes (with wide size distribution) are comparable $(\sim 1-4 \mu \mathrm{m})$ and the level of porosity is in the same range (15-20\%) while in the case of SPS, the sintering temperature is slightly lower $\left(850^{\circ} \mathrm{C}\right.$ versus $\left.900^{\circ} \mathrm{C}\right)$, the sintering dwell time significantly shorter $\left(5^{\prime}\right.$ instead of $2 \mathrm{~h}$ ) and there is no use of sintering aid. Compared to PZT ceramic sintered by SPS, the increase of porosity within the stack can be explained by a lower sintering temperature and mainly by the absence of pressure during SPS sintering of the multilayer.

a)

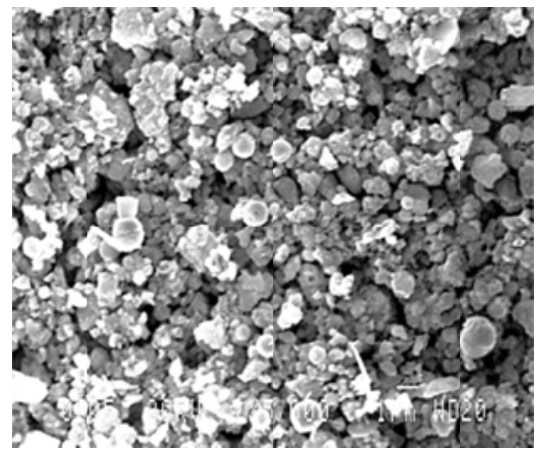

b)

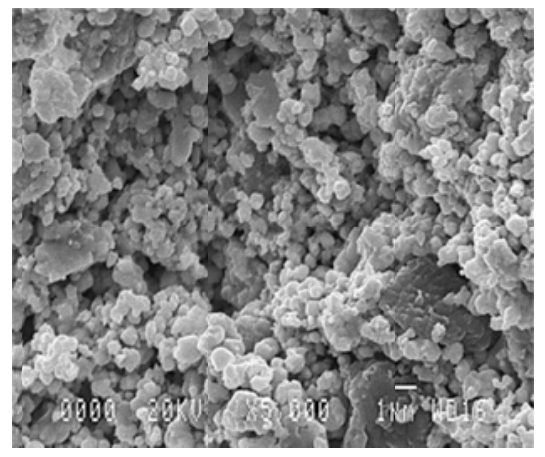

Fig. 16 a) SEM image of the active PZT layer within the Au/PZT/Au/SS sintered by SPS without sintering aid and b) SEM image of screen printed PZT thick film $\left(900^{\circ} \mathrm{C}, 2 \mathrm{~h}\right.$, sintering aid). 
Work is actually in progress to reach further improvement on densification and to tackle the problem of delamination. In conclusion of this chapter, some lines of thoughts are proposed as a guidance to overcome this last critical issue.

\section{Conclusion /perspectives}

Whatever the applications, current trends in the field of electronic components are moving towards lower costs and lower production energy. Miniaturization enabling the implementation of devices can't be overlooked and requires new technologies as well as the development of improved materials. These expectations concern in particular mechanical piezoelectric energy harvesting applications which are in development for replacing electrochemical batteries, and which are the topic of interest. In this chapter, after basics on mechanical Energy Harvesters using piezoelectric conversion, a state of the art on MEMS energy harvesters with the simple cantilever shape was led. We focused on cantilevers based on PZT ceramics or films supported on metallic substrates to highlight the advantages of thick films and metallic passive substrates for this application. We pointed out the advantages offered by screen printing thick film technology to fabricate components integrating active layers, electrodes and substrate at temperatures much lower than those used for conventional ceramic processes. The successful fabrication of piezoelectric energy harvesters, based on screen-printed PZT in sandwich between two gold electrodes and supported on a stainless steel substrate was then described. For this conventional process, the densification temperature of the PZT layer could be lowered to $900^{\circ} \mathrm{C}$ thanks to the use of the $\mathrm{LBCu}$ eutectic aid. Nevertheless the control of interfaces (metal/ceramic, metal/metal), chemistry (volatility of element, sintering aid) and densification are issues that still have to be improved. In order to avoid the use of sintering additives and to improve densification in both PZT and Au/PZT/Au/SS multilayer assembly, we aimed a strategy based on Spark Plasma Sintering. The efficiency of Spark Plasma Sintering to rapidly sinter and co-sinter materials at low temperature is no longer to be demonstrated. However, sintering oxides by SPS in vacuum (low oxygen partial pressure) can generate carbon contamination and oxygen vacancies formation that must be removed by a post annealing treatment. Our first goal in this work was to efficiently use SPS avoiding additional thermal treatment. Thanks to the use of a $\mathrm{SrCO}_{3}$ protective layer, we were able to obtain in one step highly densified PZT ceramics at $875^{\circ} \mathrm{C}$ in 5 minutes (dwell time) without sintering aid. The efficiency of the protective layer was proved through the comparison of the microstructural features and properties with PZT sintered by SPS and annealed at $800^{\circ} \mathrm{C}$. In addition, the ceramics exhibited dielectric and piezoelectric performances comparable and even better than commercial ceramics sintered at high temperature and screen-printed thick films. Our ambition was also to use SPS in one step and without sintering aid to co-sinter complex EH structure such as $\mathrm{Au} / \mathrm{PZT} / \mathrm{Au} / \mathrm{stainless}$ steel. Sintering conditions were optimized and specific mold was designed to limit interdiffusion at interfaces and ensure the uniform pressure application on the multilayer. The feasibility of the approach was demonstrated. The microstructure of the active PZT layer is similar to the one of screen-printed thick film sintered by conventional process. $\mathrm{The}^{\mathrm{SrCO}} \mathrm{O}_{3}$ protective layer was removed while keeping the integrity of the multilayer. The main challenging aspect remains the control of interfaces in terms of thermal constraints. Delamination between the active layer and the bottom gold electrode is the first issue to be solved, not only to be able to polarize the multilayer but also to guarantee the reproducibility of the process. The substrate thickness significantly affects the driving force for delamination and could be adapted to limit the constraints. The sintering temperature could be reduced in order to limit the thermal gradients but the targeted temperature window remains narrow considering both the densification of PZT and the gold paste. In this way, the transition towards $\mathrm{Ag} / \mathrm{Pd}$ electrodes could be a promising option to relax the electrode related constraint. 
Improving the PZT layer densification is also a major goal. The porosity can affect the fatigue resistance and lead to a degradation of the electromechanical properties due to the generation of cracks during cycling (Chen et al, 2018). There is some degree of freedom to improve the PZT layer densification. The use of a sintering aid such as $\mathrm{LBCu}$ would help but at this stage, this is not the preferred option since a strict control of the chemistry remains one of our priorities. Decreasing PZT grain size can be another way to enhance densification thanks to higher reactivity. In addition, it would allow to tune the properties. The domain structure depends on the grain size and the increase of grain boundaries density in fine grained ceramics will impact the domain wall motion. Hardening or softening of the piezoceramics can thus be expected. The dielectric permittivity will be also modified by changing the grain size (Randall et al, 1998). Controlling grain size would allow to find a compromise between permittivity values and electromechanical performances in order to fit with the expectations of Energy Harvesting applications.

Finally, if PZT was used here as a benchmark material, our perspectives include the transition towards lead-free piezoelectric active layer (Shrout et al, 2007). The control of chemistry during sintering will remain a critical point in particular in the case of KNN (volatility of alkali element), one of the most promising lead-free piezoelectric material (Rödel et al, 2015), but SPS investigations are already reported (Bah et al. 2014). The use of Spark Plasma Sintering to fabricate complex structures applied to

energy harvesting is still in its infancy and remains very challenging. Its successful exploitation would undoubtedly open an innovative way of designing Energy Harvesters in line with the requirements of reduction of energy consumption and sustainability.

\section{Ackowledgments}

The authors would like to thank Mario Maglione (ICMCB) for fruitful discussions, Bernard Plano (IMS) and Philippe Legros (Placamat- UMS 3626 CNRS-Université Bordeaux) for the SEM analysis and Xavier Hochart (EXELLIA-TEMEX) for the pressure step. 


\section{References}

Aktakka E E, Peterson R L and Najafi K 2011, Thinned-PZT on SOI process and design optimization for piezoelectric inertial energy harvesting, Transducer's 11 (Beijing) pp 1649-52

Anselmi-Tamburini U, J. E. Garay, and Z. A. Munir, Fundamental Investigations on the Spark Plasma Sintering/Synthesis Process III. Current Effect on Reactivity,Mater. Sci. Eng., A, 407, 24-30 (2005).

Bah H, Giovannelli F, Schoenstein F, Feuillard G, Le Clezio E, Isabelle Monot-Laffez I, High electromechanical performance with spark plasma sintering of undoped $\mathrm{K} 0.5 \mathrm{Na} 0.5 \mathrm{NbO} 3$ ceramics, Ceramics International 40, 7473, 2014

Bahraminasab M, Ghaffari S, Eslami-Shaded $\mathrm{H}, \mathrm{Al}_{2} \mathrm{O}_{3}$-Ti functionally graded material prepared by spark plasma sintering for orthopaedic applications, Journal of the Mechanical Behavior of Biomedical Materials, 72, 2017, Pages 82-89

Beeby, S P, Tudor M J, White N, Energy harvesting vibration sources for microsystems applications.Measurement Science and Technology 2006, 17 (12), R175-R195.

Beeby S, Chapter Energy Harvesting devices, in book, Resonant MEMS, Fundamentals and applications”, Brand O, Dufour I, Heinrich SM, Josse F, Advances micro and nanosystems, 2015, Wiley

Berdy DF, Srisungsitthisunti P, Peroulis D, Low-frequency meandering piezoelectric vibration energy harvester IEEE Transactions on Ultrasonics, Ferroelectrics, and Frequency Control, Volume: 59 , Issue: 5 , May 2012

Cady, W, 1946-1947, Piezoelectricity, McGraw-Hill New york

Chen C, Liang R., Zhou Z., Zhang W and Dong X., Enhanced bipolar fatigue resistance in PMN-PZT ceramics prepared by spark plasma sintering, Ceramics International 2018, 44 (4) , p 3563-3570

Chinen F, Machado I, Adamowski J, Muccillo ESN, Mucillo R, PZT consolidation by Spark Plasma Sintering (SPS), Proceedings of COBEM 2011 21st International Congress of Mechanical Engineering

Colin M, Basrour S, Rufer L, Bantignies C, Nguyen-Dinh A, Highly Efficient Low-frequency Energy Harvester Using Bulk Piezoelectric Ceramics 2013 J. Phys.: Conf. Ser. 476012133

Damjanovic D Ferroelectric, dielectric and piezoelectric properties of ferroelectric thin films and ceramics 1998, Rep. Prog. Phys. 611267

Debéda H, Lucat L and Ménil F, Influence of the densification parameters on screen-printed component properties, Journal of European Ceramic Society, 25, 12, pp.2115-2119 (2005)

Debéda H, Clément P, Llobet E and Lucat C, One-step firing for electroded PZT thick-films applied to MEMS, Smart Material structures, 2015, 24, 025020, 2015

Debéda H, Maglione M, Pommier-Budinger V, Hochart X, Sourbe W, Lucat C, Feasibibility of screen-printed PZT microceramics for Structural Health Monitoring applications, Int. J. Appl. Ceram. Technol, 11 (3) 413-421 (2014) 
Defay E, Boisseau S, Despesse G, Ch. 7 Piezoelectric materials for energy harvesting, Book Micro energy Harvesting, Edited by D.Briand, E. Yeatman and S. Roundy, Wiley-VCH, Avril 2015

Donnelly N J, Shrout TR, Randall CA, The Role of $\mathrm{Li}_{2} \mathrm{CO}_{3}$ and $\mathrm{PbO}$ in the Low-Temperature Sintering of Sr, K, Nb (SKN)-Doped PZT. J. Am. Ceram. Soc. 2009, 92, 1203-1207.

Elissalde C, Chung U C, Roulland F, Berthelot R, Artemenko A. Majimel J, Basov S, Piraux L., Nysten B., Mornet S., Aymonier C., Estournès C. and Maglione M., Specific core-shell approaches and related properties in nanostructured ferroelectric ceramics Ferroelectrics, 532, 138, 2018.

Elfrink R, Kamel TM, Goedbloed M, Matova S, Hohlfeld D, van Andel Y and van Schaijk Vibration energy harvesting with aluminum nitride-based piezoelectric devices, Journal of Micromechanics and Microengineering, Volume 19, Number 9 , 2009

Fang M H, Pan W., Wang R., Cao Z., Chen J and H. Likun, Fabrication of Cu/PZt functionally graded actuators by spark plasma sintering Materials Science Forum, Vols 423-425, pp423-426 (2003)

Fernandes E, Martin B, Rua Taborda M I, Zarabi S, Debéda H, Wei L, Salehian A, Design, Fabrication, and Testing of a Low Frequency MEMS Piezoelectromagnetic Energy Harvester. Smart Materials and Structures, IOP Publishing, 2018.

Fujii T, Tohgo K, Shinohara T, and Shimamura Y, Ceramic-metal interface fabricated by spark plasma sintering and its mechanical properties, The Proceedings of the Materials and Mechanics Conference, 2016

Gao L, Guo H, Zhang S and Randall C, Base Metal Co-Fired Multilayer Piezoelectrics Actuators, 2016, 5, 8;

Garay J E , Anselmi-Tamburini U and Munir Z A, Enhanced Growth of Intermetallic Phases in the Ni-Ti System by Current Effects, Acta Mater.,51, 4487-95 (2003).

Gilbert JM and Balouchi F, 2008, Comparison of energy harvesting systems for wireless sensor networks, Int. J. Autom. Comput., 5, 334-347

Graton O, Poulin-Vittrant G, Dahiya AS, Camara N, Tran-Huu-Hue LP and Lethiecq M, Equivalent circuit model of a nanogenerator based on a piezoelectric nanowire-polymer composite, Phys. Status Solidi RRL, vol. 7, issue 10 (2013) pp. 915-918

Han B, Zhao C, Zhu Z X,Chen X, Han Y, Hu D, Zhang MH, Thong H C, and Wang K, Temperature-Insensitive Piezoelectric Performance in $\mathrm{Pb}(\mathrm{Zr} 0.52 \mathrm{Ti0} 0.42 \mathrm{Sn} 0.02 \mathrm{Nb} 0.04) \mathrm{O} 3$ Ceramics Prepared by Spark Plasma Sintering, Appl. Mater. Interfaces, 2017, 9 (39), pp 34078-34084

Haskard M and Pitt K, Thick film technology and applications, Electrochemical Publications, 1997

Hindrichsen CC, Lou-Moeller R, Hansen K, E. Thomsen E, 2010, Advantages of PZT thick film for MEMS sensors, Sensors and Actuators A: Physical 163 (1) pp.9-14

Issindou V, Viala $\mathrm{B}$, .Gimeno $\mathrm{L}$. Cugat $\mathrm{O}$, Rado $\mathrm{C}$, Bouat $\mathrm{S}$, Fabrication methods for highperformance miniature disks of Terfenol-D for energy harvesting, Sensors and Actuators A: Physical, Volume 284, 1 December 2018, Pages 1-5 
Jaffe B, Cook WR, Jaffe H, Piezoelectric Ceramics, 8-21, Acad. press, London, 1971

Jeon Y.B. Sood R, Jeong JH, Kim S G, MEMS power generator with transverse mode thin film PZT, Sensors and actuators Physical A122 2015

Kausar A S M Z, Reza A W, Saleh M U, Ramiah H, Energizing wireless sensor networks by energy harvesting systems: Scopes, challenges and approaches, Renewable and Sustainable Energy Reviews 38 (2014) 973-989

Lakhmi R, Debéda H, Maglione M, Lucat C. Study of Screen-Printed PZT Cantilevers Both SelfActuated and Self-Read-Out, International Journal of Applied Ceramic Technology, 11:311-320, 2014.

Legallais M, Fourcade S, U.-C. Chung U C, Michau D, Maglione M, Mauvy, and Elissalde C, "Fast re-oxidation kinetics andconduction pathway in Spark Plasma Sintered ferroelectric ceramics," J. Eur. Ceram. Soc., 38, 543, 2018:

Lin S C and $\mathrm{Wu} \mathrm{W} \mathrm{J,} \mathrm{Piezoelectric} \mathrm{micro} \mathrm{energy} \mathrm{harvesters} \mathrm{based} \mathrm{on} \mathrm{stainless-steel} \mathrm{substrates} 2013$ Smart Mater. Struct. 22045016 Smart Mater. Struct. 22 (2013) 045016

Madec C, Le Gallet S, Salesse ., Geoffroy N and Bernard F , Alumina-titanium functionally graded composites produced by spark plasma sintering, Journal of Materials Processing Technology Volume 254, April 2018, Pages 277-282

Mercier A, Zehani K, Chaplier G, Pasko A, Loyau V, and Mazaleyrat F, Spark Plasma Sintering CoSintered Monolithic Transformers for Power Electronics, IEEE TRANSACTIONS ON MAGNETICS, Vol. 52, NO. 5, May 20168400404

IEEE standard on piezoelectric crystals 1961, box A, lenox hall station NY 10021 NY USA

Munir Z.A, Anselmi-Tamburini U. and Ohyanagi M. The effect of electric field and pressure on the synthesis and consolidation of materials: A review of the spark plasma sintering method, J. Mater. Sci. 41 (2006) 763-777

Monin T, Tessier-Poirier A, Léveillé E, Juneau-Fecteau A, Skotnicki T, Formosa F, Monfray S and Fréchette L 2016, First experimental demonstration of a Self-Oscillating Fluidic Heat Engine (SOFHE) with piezoelectric power generation, Journal of Physics: Conference Series pp 012039

Ochoa D.A, Suñol F, Fernando Rubio-Marcos F, Jose E. García J E, Enhancement of piezoelectric properties stability of submicron-structured piezoceramics obtained by spark plasma sintering, Journal of the European Ceramic Society 38, 4659, 2018

Paprotny I, White R and Wright P 2010 Modeling, design and fabrication of $(10 \times 10 \times 4 \mathrm{~mm} 3)$ MEMS AC energy scavenger for smart grid applications Proc. 10th Int. Workshop Micro Nanotechnol. Power Generat. Energy Convert. Appl. pp 107-10

Prashanthi K, Miriyala N, Gaikwad RD, Moussa, Rao VR, and Thundat T, Vibrational energy harvesting using photo-patternable piezoelectric nanocomposite cantilevers, Nano Energy, vol. 2, no. 5, pp. 923-932, 2013.

Quignon S, "Synthèse et caractérisations de couches minces de matériaux piézoélectriques sans plomb“, PhD Université de Valenciennes et du Hainaut-Cambresis, 2013 
Randall C A., Kim N., Kucera J P, Cao W. and Shrout T R, Intrinsic and Extrinsic Size Effects in Fine-Grained Morphotropic-Phase-Boundary Lead Zirconate Titanate Ceramics J. Am. Ceram. Soc., 81 [3] 677-88 (1998)

Rödel J, Webber K G, Dittmer R, Jo W, Kimura M, and Damjanovic D, Transferring lead-free piezelectric ceramics into application, J. of the Eur. Ceram. Soc., 35, 1659, 2015.

Roundy S, Wright P K, Rabaey J M, 2003. Energy Scavenging for Wireless Sensor Networks, Kluwer Academic Publishers, Boston MA

Roundy S and Wright P K, 2004, A Piezoelectric Vibration Based Generator for Wireless Electronics. Smart Materials and Structures, 13, 1131-1142.

Shen D, Park JH, Ajitsaria J, Choe SY, Wikle HC and Kim DJ , The design, fabrication and evaluation of a MEMS PZT cantilever with an integrated Si proof mass for vibration energy harvesting 2008 Journal of Micromechanics and Microengineering, Volume 18, Number 5

Shrout T.R. and Zhang S. J., Lead-free piezoelectric ceramics: Alternatives for PZT?, J Electroceram (2007) 19:111-124

Tadigadapa S and Mateti K, (2009), Piezoelectric MEMS sensors: state-of-the-art and perspectives, Measurement Science and Technology, 20, 092001 (30 pp).

Tang W H, Lin T K, Chen C T, Fu Y H, Lin S C, Wu W J, A High Performance Piezoelectric Micro Energy Harvester Based on Stainless Steel Substrates Journal of Physics: Conf. Series 1052 (2018) 012038

Tokita M, Development of large size ceramic/metal bulk FGM fabricated by spark plasma sintering, Materials Science Forum, 308-311 (1999) pp83-88

Tsujiura Y, Suwa E, Hida H, Suenaga K, Shibata K, Kanno I, Lead-free piezoelectric MEMS energy harvesters of stainless steel cantilevers, Transducers 2013, Barcelona, SPAIN, 16-20 June 2013

Yeo HG, Trolier-McKinstrya S, Effect of piezoelectric layer thickness and poling conditions on the performance of cantilever piezoelectric energy harvesters on Ni foils, Sensors and Actuators A: Physical, Volume 273, 15 April 2018, Pages 90-97

Wang Q, Z.P. Cao ZP, H. Kuwano H, Metal-based piezoelectric energy harvesters by direct deposition of PZT thick films on stainless steel Micro \& Nano Letters Author(s): Source: Volume 7, Issue 12, December 2012, p. 1158 - 1161

Wang XX, Murakami K, Sugiyama O, Kaneko S, Piezoelectric properties, densification behavior and microstructural evolution of low temperature sintered PZT ceramics with sintering aids, J Eur. Cer. Soc., 21 (2001), pp. 1367-1370

Wang P, Shi S, and $\mathrm{Du} \mathrm{H}$, Fabrication and performance of $\mathrm{ZnO}$ piezoelectric cantilever for vibration energy harvesting, in Piezoelectricity, Acoustic Waves, and Device Applications (SPAWDA), 2015 Symposium on, 2015, pp. 147-151.

aWu Y.J, Kimura R, Uekawa N, Kakegawa K and Sasaki Y., Spark Plasma Sintering of Transparent PbZrO3-PbTiO3-Pb(Zn1/3Nb2/3)O3 Ceramics, Jpn. J. Appl. Phys. Vol. 41 (2002) pp. L 219-L 221

bWu Y J, Uekawa N, Kakegawa K, Sasaki, Y. 2002, Compositional fluctuation and dielectric properties of $\mathrm{Pb}(\mathrm{Zr} 0.3 \mathrm{Ti} 0.7) \mathrm{O} 3$ ceramics prepared by spark plasma sintering, Materials Letters. Vol. 57, pp. 771-775 
Xu R, Lei A, Dahl-Petersen C, Hansen K, Guizzetti M, Birkelund K, Thomsen EV, Hansen O, 2012 "Screen printed PZT/PZT thick film bimorph MEMS cantilever device for vibration energy harvesting", Sensors and Actuators A Physical 188 pp.383-388

Yang Z Zarabi S Fernandes E Rua Taborda MI Hélène Debéda H, Salehian A, Nairn D, Wei L, A Simple Wireless Sensor Node System for Electricity Monitoring Applications: Design, Integration, and Testing with Different Piezoelectric Energy Harvesters, Sensors, MDPI, 2018, Special Issue Low Energy Wireless Sensor Networks: Protocols, Architectures and Solutions, 18(11), 3733

Zeng, W, Shu L, Li Q, Chen, S, Wang, F, Tao, X M, Fiber-Based Wearable Electronics: A Review of 335 Materials, Fabrication, Devices, and Applications. Adv. Mater. 2014, 26, 5310-5336, 336

Zhu D, Beeby S and Tudor M N R. Harris, A credit card sized self powered smart sensor node Sensors and Actuators A Physical, vol. 169, pp. 317-325 (2011) 